\section{D) Check for updates}

Cite this: Food Funct., 2018, 9, 5950

\title{
Anti-inflammatory effects of cinnamon extract and identification of active compounds influencing the TLR2 and TLR4 signaling pathways $\uparrow$
}

\author{
Anne Schink, $\ddagger^{\mathrm{a}}$ Katerina Naumoska, id $\ddagger^{\mathrm{a}}$, ${ }^{\mathrm{b}}$ Zoran Kitanovski, ${ }^{a}$ \\ Christopher Johannes Kampf, (D) a,c Janine Fröhlich-Nowoisky, (D) a \\ Eckhard Thines, ${ }^{d, e}$ Ulrich Pöschl, (D) a Detlef Schuppan $\S^{f, g}$ and Kurt Lucas (D) * $\S^{a}$
}

Purpose: Inflammatory processes are involved in many diseases. The bark of Cinnamomum verum and its extracts are well known for anti-inflammatory effects, but the underlying active compounds and chemical mechanisms are not yet fully identified. The objective of this study was to elucidate how cinnamon extract, specifically active compounds, and their combinations influence the signaling pathways of inflammation, especially through toll-like receptors TLR2 and TLR4. Methods: Bioassay-guided fractionation was performed for standard ethanolic cinnamon extract using high performance liquid chromatography followed by compound identification in the determined active fractions by high-resolution mass spectrometry and gas chromatography-mass spectrometry. THP-1 monocytes were pre-incubated with cinnamon extract, cinnamon fractions or its compounds and stimulated with lipopolysaccharides (LPS), followed by determination of interleukin 8 (IL-8) secretion, and phosphorylation of protein kinase B (Akt),

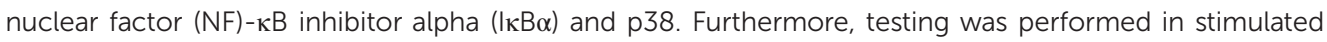
HEK-TLR2 and HEK-TLR4 reporter cells for direct receptor agonistic effects. Results: Among the identified compounds, trans-cinnamaldehyde and p-cymene significantly reduced the LPS-dependent IL-8 secretion in THP-1 monocytes. Synergistic anti-inflammatory effects were observed for combinations of trans-cinnamaldehyde with $p$-cymene, cinnamyl alcohol or cinnamic acid. Moreover, cinnamon extract as well as trans-cinnamaldehyde and $p$-cymene mitigated the phosphorylation of Akt and $I_{\kappa} B \alpha$. Conclusions: Trans-cinnamaldehyde and $p$-cymene contribute to the strong anti-inflammatory effects of cinnamon extract. Furthermore, our experiments indicate that also synergistic effects among compounds that do not exhibit anti-inflammatory effects themselves might be present to positively influence the beneficial effects of cinnamon bark extract.

Received 28th June 2018 Accepted 24th October 2018 DOI: $10.1039 / \mathrm{c} 8 \mathrm{fo} 01286 \mathrm{e}$ rsc.li/food-function

\footnotetext{
${ }^{a}$ Multiphase Chemistry Department, Max Planck Institute for Chemistry, Hahn-Meitner-Weg 1, 55128 Mainz, Germany.E-mail:k.lucas@mpic.de; Tel: +4961313057700

${ }^{b}$ Department of Food Chemistry, National Institute of Chemistry, Hajdrihova 19, 1001 Ljubljana, Slovenia

${ }^{c}$ Institute of Organic Chemistry, Johannes Gutenberg University Mainz, Duesbergweg 10-14, 55128 Mainz, Germany

${ }^{d}$ Institut für Biotechnologie und Wirkstoff Forschung gGmbH,

Erwin-Schrödinger-Straße 56, Kaiserslautern, Germany

${ }^{e}$ Institute of Molecular Physiology, Johannes Gutenberg University Mainz,

Johannes-von-Müller-Weg 6, Mainz, Germany

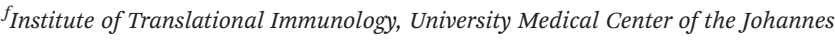
Gutenberg University, Langenbeckstraße 1, 55131 Mainz, Germany

${ }^{g}$ Division of Gastroenterology, Beth Israel Deaconess Medical Center,

Harvard Medical School, 330 Brookline Ave, Boston, MA 02215, USA

$\dagger$ Electronic supplementary information (ESI) available. See DOI: 10.1039/ c8fo01286e

\$These authors contributed equally to this work.

$\S$ Equal senior authorship.
}

\section{Introduction}

Regardless of the origin, inflammatory activities on the molecular level can be described as variations of a cyclic process, involving innate immune activation. Toll-like receptors, like TLR2 and TLR4, can sense both Pathogen-associated and Damage-associated molecular pattern (PAMP, DAMPs) and once activated, they trigger the secretion of pro-inflammatory cytokines such as IL-1 $\beta$ and tumor necrosis factor (TNF- $\alpha$ ), the generation of reactive oxygen and nitrogen species (ROS, RNS) and the release of DAMPs. These molecules cause in turn additional receptor stimulation, which provoke further immune responses. ${ }^{1,2}$ The activation of TLR4 and the translocation of the transcription factor NF- $\mathrm{kB}$ into the cell nucleus play a key role in inflammation and chronic diseases. Molecules within the TLR4 signaling cascade are e.g. IкB $\alpha$, the serine/threonine kinase Akt and mitogen-activated protein 
(MAP) kinase p38, who can activate the transcription factors NF- $\mathrm{KB}$ and/or activator protein 1 (AP-1). Both transcription factors contribute to the expression of several pro-inflammatory cytokines, e.g. IL-1, IL-6, IL-8 and TNF- $\alpha .{ }^{3,4}$ Acute and chronic inflammation are part of many severe inflammatory diseases, including autoimmune diseases, allergies, organ fibrosis and dysfunction. ${ }^{5-8}$ Some synthetic substances, e.g. eritoran and TAK-242 (Resatorvid), inhibit TLR4 signaling via the intravenous route and are explored for the treatment of sepsis. ${ }^{9-11}$ Some natural compounds, e.g. epigallocatechin-3gallate and 6-shogaol are modestly TLR4 inhibitory, but also regulate many other pathways. ${ }^{11-13}$ However, to date, no effective orally active TLR4 antagonists are accessible for clinical usage.

Natural compounds have been used since ancient times in traditional medicines, but their potential to modulate inflammatory pathways has only recently been discovered. ${ }^{14}$ The dried bark of Cinnamomum verum (Lauraceae), an evergreen tall tree, is one of the oldest known spices. Besides the usage as natural flavoring and fragrance additive in food, beverages and perfumes, cinnamon has also been used in traditional medicine, e.g. for prevention of nausea and vomiting, as treatment of common cold, cardiovascular diseases, chronic gastrointestinal disorders, or as general stimulant. Different cinnamon species are reported to be used in food industry and/or traditional and modern medicine, e.g. Cinnamomum cassia, Cinnamomum verum, Cinnamomum burmanii, Cinnamomum loureirii, Cinnamomum tamala and Cinnamomum cordatum. The preferred cinnamon species in food industry is Cinnamomum verum, whereas in the pharmaceutical industry, Cinnamomum cassia and Cinnamomum verum are used interchangeably. ${ }^{15}$ From current literature, cinnamon extract is known to possess anti-inflammatory effects in a mouse model of alcohol-induced fatty liver, on colitis in mice with IL-10 knockout, ${ }^{16-18}$ in models of arthritis and diabetes ${ }^{19,20}$ and in experimental autoimmune encephalitis (EAE), a model of multiple sclerosis. ${ }^{21}$ Ethanolic extracts of Cinnamomum verum have shown anti-inflammatory properties by suppression of nitric oxide (NO), TNF- $\alpha$, IL-1 $\beta$ and IL-6 production as well as blocking the activation of NF- $\mathrm{KB}$ in different LPS-stimulated cells. $^{22,23}$ Trans-cinnamaldehyde has been identified as major active compound in Cinnamomum verum bark extract, ${ }^{24}$ with reported anti-neuroinflammatory, ${ }^{22}$ antiallergic, ${ }^{25}$ anticancer, antifungal, antidiabetic and general anti-inflammatory effects. ${ }^{25-28}$ Despite some toxicity at high doses of cinnamaldehyde, this compound is considered safe and well tolerated in humans and animals. An acceptable daily intake of $1.25 \mathrm{mg}$ $\mathrm{kg}^{-1}$ is suggested by the food and drug administration (FDA) and European food safety authority (EFSA). ${ }^{27}$ Suppression of TLR4 receptor dimerization is described as one mechanism of the anti-inflammatory effects of cinnamaldehyde,${ }^{29}$ but cinnamaldehyde also mediates TLR4-independent beneficial effects e.g. in diabetes by upregulation of peroxisome proliferator-activated receptor gamma (PPAR $\gamma)$ gene expression. ${ }^{30}$ Coumarin, another phytochemical, is one of the more critical compounds that can be present in cinnamon and is reported to possess hepatotoxic and carcinogenic properties. A tolerable daily intake (TDI) of $0.1 \mathrm{mg}$ coumarin per $\mathrm{kg}$ bodyweight has been established by the EFSA. ${ }^{31,32}$ The content of coumarin within the different cinnamon species strongly varies. Rather low concentrations (from below detection limit up to $297 \mathrm{mg} \mathrm{kg}^{-1}$ ) can be found in Cinnamomum verum, whereas Cinnamomum cassia contains markedly more coumarin (from $1740 \mathrm{mg} \mathrm{kg}^{-1}$ up to $\left.7670 \mathrm{mg} \mathrm{kg}^{-1}\right) .^{33}$ In addition to cinnamaldehyde, further compounds present in cinnamon extract, e.g. o-methoxycinnamaldehyde, cinnamyl alcohol, benzyl benzoate, eugenol and cinnamic acid also showed anti-inflammatory properties by inhibiting NO production. Cinnamaldehyde, o-methoxycinnamaldehyde and benzyl benzoate also induced a strong inhibition of TNF- $\alpha$ production. ${ }^{24}$ Further studies confirmed the cinnamaldehyde-dependent inhibition of pro-inflammatory cytokine secretion. ${ }^{34,35}$ Cinnamon extract, a complex natural matrix, may contain additional compounds contributing to the strong anti-inflammatory activity. Moreover, its biological activities may be positively or negatively modulated by such other compounds. Therefore, the objective of this work was to study the anti-inflammatory effects of Cinnamomum verum extract and to identify further compounds or combinations of compounds contributing to its potent (TLR-mediated) antiphlogistic activity.

\section{Materials and methods}

\section{Cell cultures and treatments}

THP-1 cell line. The THP-1 monocyte-macrophage cell line TIB-202 (ATCC) was cultured in RPMI 1640 medium (Thermo Fisher Scientific, Darmstadt, Germany) supplemented with $10 \%$ fetal calf serum (FCS; heat-inactivated) (Biochrom, Berlin, Germany), $1 \%$ penicillin/streptomycin (Thermo Fisher Scientific) and $0.05 \mathrm{mM} \beta$-mercaptoethanol (Sigma-Aldrich, Darmstadt, Germany) in a humidified atmosphere of $5 \% \mathrm{CO}_{2}$ at $37^{\circ} \mathrm{C} .100 \mu \mathrm{l}$ with $4 \times 10^{5}$ cells per $\mathrm{ml}$ were seeded in wells of a 96-well microtiter plate (Greiner Bio-One, Solingen, Germany) and allowed to settle for $1 \mathrm{~h}$. Cell culture experiments with cinnamon extract $(70 \%$ aqueous ethanolic extract of Cinnamomum verum bark, Tinctura Cinnamomi (1:5); Maros Arznei, Fürth, Germany) were performed within a concentration range from $0.03 \%$ to $3 \%$ extract in cell culture medium or with the same amount of vehicle, $70 \%$ aqueous ethanol. Stock solutions with concentration of $4 \mathrm{mg} \mathrm{m}^{-1}$ of $p$-cymene, methyl salicylate, cinnamyl alcohol, trans-cinnamic acid, benzoic acid, trans-cinnamaldehyde, stearic acid and palmitic acid (all Sigma-Aldrich, analytical grade) were prepared in $70 \%$ aqueous ethanol. Final concentrations of $25 \mu \mathrm{g} \mathrm{ml} \mathrm{m}^{-1}$ substance or the same amount of vehicle were used in cell culture medium. In experiments with isolated cinnamon highperformance liquid chromatographic (HPLC) fractions, $2 \times$ $250 \mu \mathrm{l}$ of the fractions were dried by SpeedVac (Martin Christ, Osterode, Germany) in a 96-well microtiter plate. After disinfection of the plate with $70 \%$ aqueous ethanol, $4 \times 10^{5}$ cells per $\mathrm{ml}$ were seeded, shaken for $10 \mathrm{~min}$ and were allowed to 
settle for $1 \mathrm{~h}$. In all experiments, cells were incubated with extract, compounds or fractions for $2 \mathrm{~h}$ at $37^{\circ} \mathrm{C}$, followed by a stimulation of TLR4 with LPS (LPS-EB; from E. coli O111:B4, Invivogen, Toulouse, France) at a final concentration of $50 \mathrm{ng}$ $\mathrm{ml}^{-1}\left(4 \mathrm{~h}\right.$ at $\left.37^{\circ} \mathrm{C}\right)$.

HEK-TLR2 and HEK-TLR4 cell lines. HEK-Blue hTLR2 cell line (HEK-TLR2) and HEK-Blue hTLR4 cell line (HEK-TLR4) (both Invivogen) were cultured in Dulbecco's Modified Eagle Medium (DMEM) high glucose supplemented with 10\% FCS (heat-inactivated), $1 \%$ penicillin/streptomycin and $1 \times$ HEK-Blue Selection (Invivogen) in a humidified atmosphere of $5 \% \mathrm{CO}_{2}$ at $37{ }^{\circ} \mathrm{C}$. To determine viability, HEK-Blue cells were cultured in the medium described above but without HEK-Blue Selection. For TLR2 and TLR4 responsiveness, cells were cultured in HEK-Blue Detection medium (Invivogen). In 96-well microtiter plates, cinnamon extract (concentration range from $0.01 \%$ to $3 \%$ extract in cell culture medium), $25 \mu \mathrm{g} \mathrm{ml} \mathrm{m}^{-1}$ defined compound or the same amount of vehicle $70 \%$ aqueous ethanol were added, followed by seeding of $180 \mu \mathrm{l}$ per well each with $2.8 \times 10^{5}$ cells per ml. Cells were incubated for $2 \mathrm{~h}$ at $37^{\circ} \mathrm{C}$, followed by specific stimulation of receptors with $1 \mathrm{ng} \mathrm{ml} \mathrm{m}^{-1}$ $S$-[2,3-bis(palmitoyloxy)-(2RS)-propyl]-[R]-cysteinyl-[S]-seryl-[S]lysyl-[S]-lysyl-[S]-lysyl-[S]-lysine (Pam2CSK4, HEK-TLR2 cell line; Invivogen) or $100 \mathrm{ng} \mathrm{ml^{-1 }}$ LPS-EB Ultrapure (HEK-TLR4 cell line; LPS from E. coli O111:B4, Invivogen) over night at $37{ }^{\circ} \mathrm{C}$. Cell viability was measured in both cell lines using the Alamar Blue Assay (Thermo Fisher Scientific) and TLR2/TLR4 activation using HEK-Blue Detection Assay (Invivogen).

\section{Determination of cell viability by the Alamar Blue Assay}

The Alamar Blue Assay (Thermo Fisher Scientific) was used according to manufacturer's protocol (10\% final concentration of Alamar Blue solution in cell culture medium; incubation overnight at $37^{\circ} \mathrm{C}$ ). Fluorescence intensity was measured with a microplate reader (Synergy Neo, Biotek, Bad Friedrichshall, Germany) at an excitation wavelength of $560 \mathrm{~nm}$ and an emission wavelength of $590 \mathrm{~nm}$.

\section{Determination of IL-8 concentration by ELISA}

IL-8 concentration in supernatant of pre-treated THP-1 monocytes was determined using ELISA (BD Biosciences). The sandwich ELISA was performed according to the manufacturer's protocol with optimized washing buffer volume. Supernatant $(70 \mu \mathrm{l}$ per well) was diluted with $30 \mu \mathrm{l}$ assay diluent to ensure IL-8 concentration within detection range. Absorbance was measured using a Synergy Neo plate reader (Biotek) at a wavelength of $450 \mathrm{~nm}$ and a reference wavelength of $570 \mathrm{~nm}$. The program SynergyNeo (Biotek) was used to determine a standard curve (4 parameter logarithmic) per plate with the pipetted standard values. IL-8 concentration of the samples was calculated according to standard curve and dilution factor.

\section{Phosphoprotein determination}

Phosphorylation level of Akt, p38 and $\mathrm{I} \kappa \mathrm{B} \alpha$ in pre-treated THP-1 monocytes were determined by sodium dodecyl sulfatepolyacrylamide gel electrophoresis (SDS-PAGE) followed by
Western Blot analysis. For preparation of a cell lysate, THP-1 monocytes were centrifuged for $5 \mathrm{~min}$ at $300 \mathrm{~g}$, followed by washing with $500 \mu \mathrm{l}$ PBS. After another centrifugation for $5 \mathrm{~min}$ at $300 \mathrm{~g}$, the cell pellet was resuspended in $2 \times$ Laemmli sample buffer. The samples were boiled for $10 \mathrm{~min}$ at $100{ }^{\circ} \mathrm{C}$ and centrifuged for $10 \mathrm{~min}$ at $13000 \mathrm{~g}$. Protein concentration of the supernatant was measured using the bicinchoninic acid (BCA) assay (Thermo Fisher Scientific) according to the manufacturer's protocol. $15 \mu \mathrm{g}$ cell lysates were separated by a $10 \%$ SDS-polyacrylamide gel and transferred onto $0.2 \mu \mathrm{m}$ nitrocellulose membranes (Bio-Rad Laboratories, München, Germany). Afterwards, the membranes were blocked with 5\% fat-free milk powder (Cell Signaling Technology, Leiden, The Netherlands) in Tris-buffered saline with $0.05 \%$ Tween-20 (TBS-T) for $1 \mathrm{~h}$ at RT. The membranes were incubated overnight at $4{ }^{\circ} \mathrm{C}$ with the specific primary antibodies for vinculin (mouse, 1:2500; Abcam, Cambridge, UK), tubulin (rat, 1:10 000; Abcam), Akt (pan, 11E7, rabbit, 1:500; Cell Signaling Technology), phospho-Akt (Ser473, D9E, rabbit, 1:1000; Cell Signaling Technology), IкB $\alpha$ (mouse, 1:1000; Cell Signaling Technology), phospho-IкB $\alpha$ (Ser36, 1:30 000, rabbit; Abcam), p38 (9F12, mouse, 1:267; Santa Cruz Biotechnology, Heidelberg, Germany) or phospho-p38 (E-1, mouse, $1: 1000$; Santa Cruz Biotechnology), each diluted in 5\% fat-free milk powder solution. After $3 \times 5$ min washing with TBS-T, membranes were incubated with the horseradish peroxidasecoupled secondary antibodies mouse-IgG, rabbit-IgG or rat-IgG (all goat, 1:10 000; Dianova, Hamburg, Germany) for $2 \mathrm{~h}$ at RT, each diluted in TBS-T. Afterwards, membranes were washed $5 \times 5$ min with TBS-T, followed by development of the protein bands using an enhanced chemiluminescence system ECL-plus (Thermo Fisher Scientific) according to manufacturer's protocol.

\section{Determination of transcription activity in HEK-Blue cells}

The inducible reporter gene secreted embryonic alkaline phosphatase (SEAP) of the HEK-TLR2 cell line is under control of the IFN $\beta$ minimal promoter fused to five NF- $\mathrm{B}$ and AP 1 binding sides. The SEAP of the HEK-TLR4 cell line is under control of the IL-12 p40 minimal promoter fused to five NF- $\kappa B$ and AP-1 binding sides (InvivoGen). Production of SEAP was determined using the HEK-Blue Detection Assay. Pre-treated cells, which were cultured in HEK-Blue Detection medium, were measured for their TLR2 stimulation (HEK-TLR2 cell line) and TLR4 stimulation (HEK-TLR4 cell line) using a Synergy Neo plate reader at a wavelength of $640 \mathrm{~nm}$.

\section{Fractionation of the cinnamon extract}

Cinnamon extract $(70 \%$ aqueous ethanolic extract of Cinnamomum verum bark, Tinctura Cinnamomi (1:5); Maros Arznei, Fürth, Germany) was fractionated by a preparative HPLC-DAD (Agilent 1260 Infinity; Agilent Technologies, Waldbronn, Germany) system equipped with a fraction collector. For this purpose, an HPLC-UV method was developed on a Zorbax Eclipse XDB C18 column $(150 \times 4.6 \mathrm{~mm} ; 5 \mu \mathrm{m}$; Agilent Technologies) connected to a security guard C18 column 
(Agilent). Gradient elution with a mobile phase composed of $0.1 \%$ formic acid in water (A) (Sigma-Aldrich) and acetonitrile (B) (Fisher Scientific) was applied at $25{ }^{\circ} \mathrm{C}$ and a flow rate of

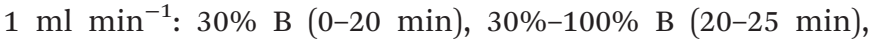
100\% B (25-45 $\mathrm{min}), \quad 100 \%-30 \% \mathrm{~B} \quad(45-47 \mathrm{~min}), \quad 30 \% \mathrm{~B}$ (47-60 min). Before injection $(400 \mu \mathrm{l}), 70 \%$ aqueous ethanolic cinnamon extract was diluted with water (Milli-Q, Millipore, Darmstadt, Germany) at a ratio $1: 3 v / v$ and filtered through a Corning ${ }^{\circledR}$ Costar ${ }^{\circledR}$ Spin- $\mathrm{X}{ }^{\circledR}$ polypropylene centrifuge tube filters with $0.22 \mu \mathrm{m}$ cellulose acetate membranes (SigmaAldrich). Chromatograms were acquired at several UV wavelengths (210 nm, $250 \mathrm{~nm}, 280 \mathrm{~nm}$ and $300 \mathrm{~nm}$ ), using UV/Vis DAD.

\section{Identification of compounds in the anti-inflammatory fractions}

Cinnamon extract fractions with anti-inflammatory properties, determined by cell culture-based assays, were further analyzed using high-resolution mass spectrometry (HRMS) and gas chromatography-mass spectrometry (GC-MS). For the HRMS analysis (Agilent 1260 Infinity coupled to Agilent Technologies 6540 UHD Accurate-Mass quadrupole-time-of-flight (Q-TOF) LC/MS), fractions (1 ml) were evaporated until dryness, redissolved in absolute ethanol (40 $\mu \mathrm{l}$; Sigma-Aldrich) and injected into the mass spectrometer (without using a column). The analysis was performed using acetonitrile/0.1\% aqueous formic acid $(7 / 3, v / v)$ as a mobile phase at a flow rate of $0.2 \mathrm{ml} \mathrm{min}^{-1}$. The injection volume was $10 \mu \mathrm{l}$. Electrospray ionization (ESI) in positive and negative ion mode was used for ionization of the compounds in the extract fractions. Source conditions were as follows: gas and sheath gas temperatures $325{ }^{\circ} \mathrm{C}$ and $295{ }^{\circ} \mathrm{C}$, respectively, drying gas $51 \mathrm{~min}^{-1}$, sheath gas flow $121 \mathrm{~min}^{-1}$, nebulizer gas $20 \mathrm{psig}$, capillary and nozzle voltages $3500 \mathrm{~V}$ and $2000 \mathrm{~V}$, respectively. The Q-TOF MS conditions were the following: fragmentor $176 \mathrm{~V}$, skimmer $46 \mathrm{~V}$, Oct $1 \mathrm{RF}$ $\mathrm{Vpp} 750 \mathrm{~V}$. MS and $\mathrm{MS}^{2}$ spectra were recorded in the $\mathrm{m} / \mathrm{z}$ range $20-800$. Collision energy of $30 \%$ was used to fragment the precursor ions observed in the MS spectra.

GC-MS (HP 6890 gas chromatograph coupled to a single quadrupole HP 5972 mass spectrometer, Hewlett-Packard) was used to further separate compounds from the anti-inflammatory HPLC fractions on a DB-5MS + DG column $(30 \mathrm{~m} \times$ $0.250 \mathrm{~mm}$ I.D.; $0.25 \mu \mathrm{m}$, Agilent (J\&W)) using a split injection ( $1: 1$ ratio) at an injection volume of $1 \mu$ l and an injector temperature of $260^{\circ} \mathrm{C}$. The GC oven program was as follows: hold at $50{ }^{\circ} \mathrm{C}$ for $1 \mathrm{~min}$, then heating at $4^{\circ} \mathrm{C} \mathrm{min}^{-1}$ rate to $300{ }^{\circ} \mathrm{C}$ and final hold at $300^{\circ} \mathrm{C}$ for $15 \mathrm{~min}$. The temperature of the GC-MS transfer line was set at $290{ }^{\circ} \mathrm{C}$. Helium (>99.9999\%, Messer) was used as carrier gas with a constant flow of $1.2 \mathrm{ml} \mathrm{min} \mathrm{m}^{-1}$. Electron impact ionization (EI) mass spectra were recorded at ionization energy of $70 \mathrm{eV}$. Recorded chromatograms in the $\mathrm{m} / \mathrm{z}$ range 35-600 were processed using a NIST 2005 mass spectral library. Compounds present in the anti-inflammatory fractions were separated and analyzed both in non-derivatized and derivatized form (silylated with trimethylsilyl methallylsulfinate (SILMAS); Sigma-Aldrich). The solvent from the non-deri- vatized HPLC fractions $(1 \mathrm{ml})$ was evaporated and redissolved in absolute ethanol ( $40 \mu \mathrm{l} ; \geq 99.8 \%$, GC). To derivatize the polar compounds in the HPLC fractions, they $(1 \mathrm{ml})$ were first dried under nitrogen, followed by reconstitution of the residue in $200 \mu \mathrm{l}$ dichloromethane (Roth) and subsequent addition of $200 \mu \mathrm{l}$ SILMAS reagent. After $10 \mathrm{~min}$, derivatized HPLC fractions were finally dried under nitrogen and redissolved in dichloromethane $(500 \mu \mathrm{l})$.

\section{Statistical analysis}

Analysis of variance (ANOVA) was performed to analyze variance between different experimental groups. Unpaired $t$-test using GraphPad Prism version 5.01 for Windows (GraphPad Software, San Diego, California, USA, http://www.graphpad. com) was performed to test the statistical significance of the results. $P<0.05$ was considered significant. In all graphs, error bars depict standard deviation.

\section{Results}

\section{Dose-dependent anti-inflammatory effects of cinnamon extract on TLR pathways}

To analyze whether cinnamon extract interferes with TLR signaling pathways in in vitro, THP-1 monocytes were incubated with cinnamon extract, followed by LPS-stimulation. Viability of cells treated with varying concentrations was above $92 \%$ in all cases compared with untreated cells (Fig. 1a). Since small amounts of ethanol are reported to result in a reduced LPSdependent TLR4 response, ${ }^{36}$ which was also observed in our experiments (Fig. 1b), IL-8 secretion of ethanol-treated THP-1 monocytes (Fig. 1c) was set to $100 \%$ to display only cinnamon-dependent effects. A dose-dependent decrease of IL-8 secretion was observed in THP-1 monocytes treated with cinnamon extract compared to control. High viability of the cells largely excluded any toxic effects of the cinnamon extract that may have affected IL-8 secretion. Treatment with $0.6 \%, 1 \%$ and $3 \%$ cinnamon extract resulted in dose-dependently decreased IL-8 secretion normalized to viability when compared to the ethanol control (Fig. 1d).

Furthermore, the potency of cinnamon extract to specifically inhibit the TLR4 receptor was tested using a comparative assay with Pam2CSK4 (a TLR2 ligand)-stimulated HEK-TLR2 and LPS-EB Ultrapure (a TLR4 ligand)-stimulated HEK-TLR4 cells. Since the nature of their intracellular signaling cascade upon stimulation is partly comparable, differences in their inflammatory response should be related to direct interference with TLR4. Viability of HEK-TLR2 and HEK-TLR4 cells treated with $0.01 \%$ to $3 \%$ cinnamon extract was above $80 \%$ compared to respective ethanol-treated cells (Fig. 2a). A comparable dosedependent decrease of NF- $\kappa \mathrm{B}$ and AP-1 activation normalized to viability was observed in both activated cell lines after incubation with cinnamon extract (Fig. 2b), which was significant for treatment with $0.3 \%$ to $3 \%$ cinnamon extract compared to the respective ethanol control. No significant differences 

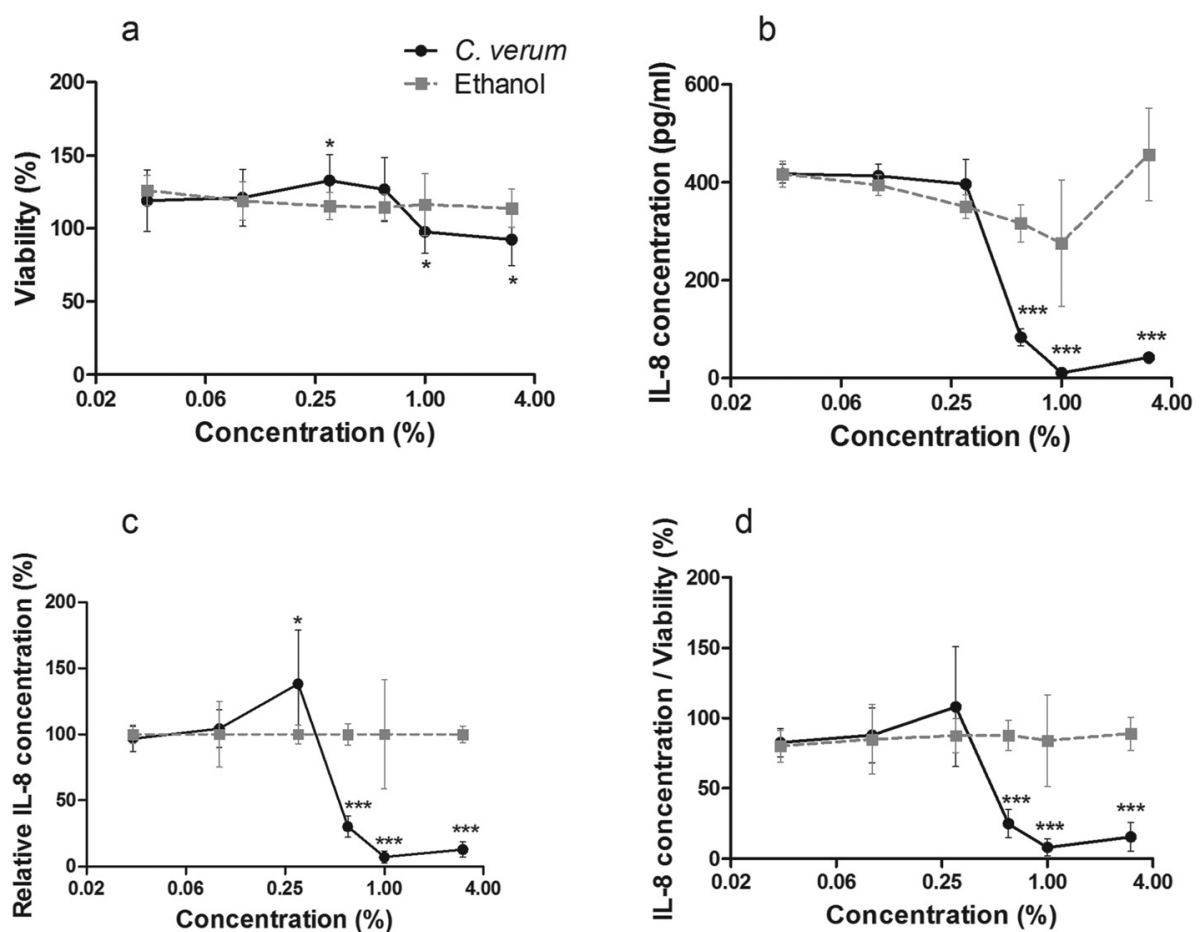

Fig. 1 Dose-dependent viability and anti-inflammatory effects of cinnamon extract in THP-1 monocytes. THP-1 monocytes were incubated with cinnamon extract or vehicle (70\% ethanol), followed by stimulation of TLR4 activity with LPS-EB. a: Viability was measured using the Alamar Blue

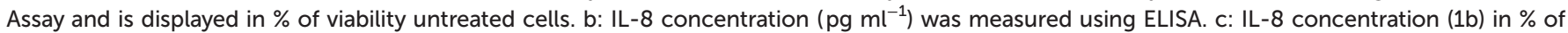
corresponding vehicle-treated cells. d: IL-8 secretion (1c) divided by viability (1a). All figures: data represent means \pm SD ( $n=9$ ); unpaired $t$-test with ${ }^{*} p<0.05,{ }^{* *} p<0.0005$ compared to respective ethanol control.
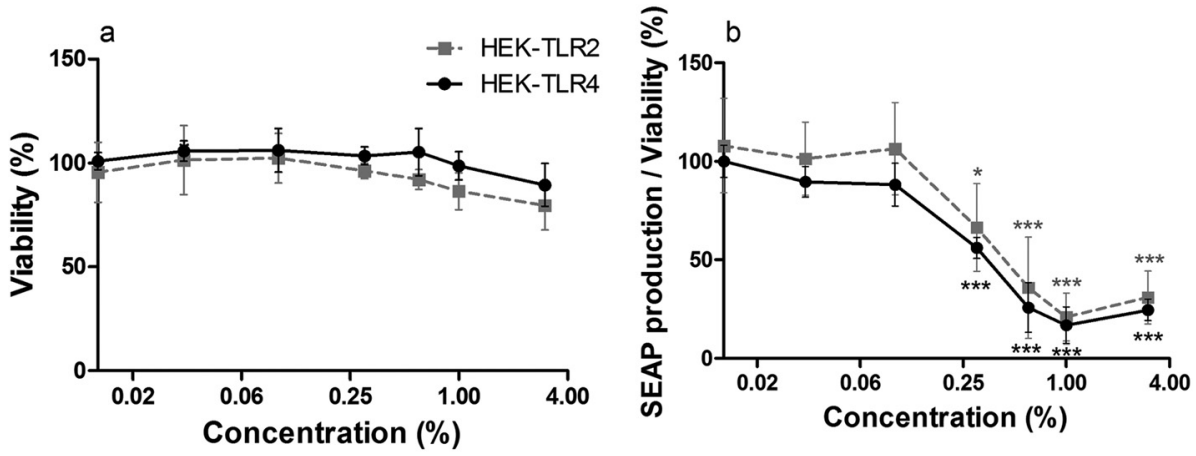

Fig. 2 Dose-dependent viability and anti-inflammatory effects of cinnamon extract in HEK-TLR2 and HEK-TLR4 cells. HEK-TLR2 cells (grey, dashed line) and HEK-TLR4 cells (black, full line) were incubated with cinnamon extract or vehicle (70\% ethanol), followed by stimulation of TLR2 with Pam2CSK4 (HEK-TLR2 cells) or TLR4 with LPS-EB Ultrapure (HEK-TLR4 cells). a: Viability was measured using the Alamar Blue Assay and is displayed in \% of ethanol-treated cells. b: TLR2 or TLR4 receptor response were determined measuring NF- $\kappa \mathrm{B}$ - and AP-1-dependent SEAP production normalized to ethanol control and divided by viability (2a). All figures: data represent means $\pm \operatorname{SD}(n=5)$; unpaired $t$-test: ${ }^{*} p<0.05$, ${ }^{* * *} p<0.001$ compared to respective ethanol control, no significance in comparison between cell lines.

occurred when comparing the inflammatory activity between both cell lines.

\section{Fractionation of cinnamon extract and identification of anti- inflammatory compounds}

To identify all major compounds responsible for specific antiinflammatory effects, cinnamon extract was fractionated using preparative HPLC-DAD (Fig. 3). Fifteen fractions (A-O;
Table $\mathrm{S} 1 \dagger$ ) were collected and tested for their anti-inflammatory potential in cell culture-based analysis. Seven fractions induced a significant reduction of IL-8 secretion normalized to viability in LPS-stimulated THP-1 monocytes (Fig. 4). The fractions that showed a TLR4 response below $77 \%$ of the respective solvent controls were further analyzed using HRMS and GC-MS.

HRMS spectra of the fractions acquired in both positive $(+)$ and negative (-) ion mode, usually showed complex ion pat- 


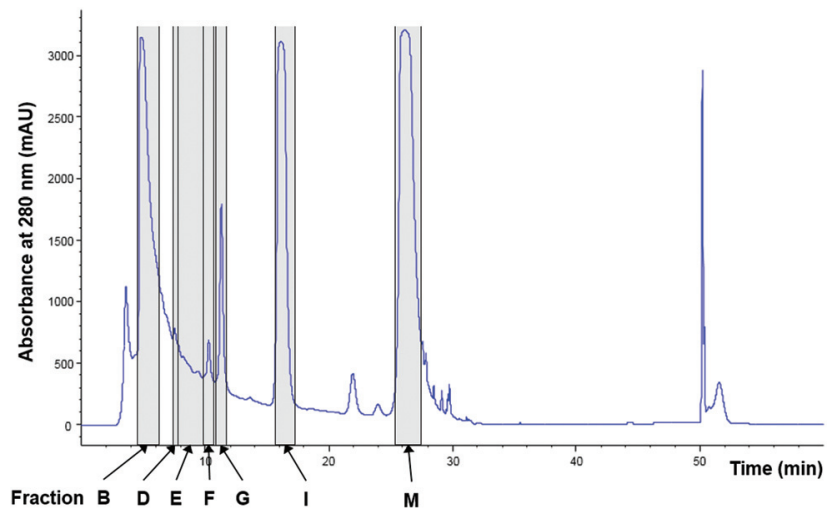

Fig. 3 Fractionation of cinnamon extract using HPLC-DAD. Chromatogram of cinnamon extract fractionation at wavelength of $280 \mathrm{~nm}$. Marked in grey: cinnamon fractions with anti-inflammatory effects in LPS-stimulated THP-1 monocytes (Fig. 4).

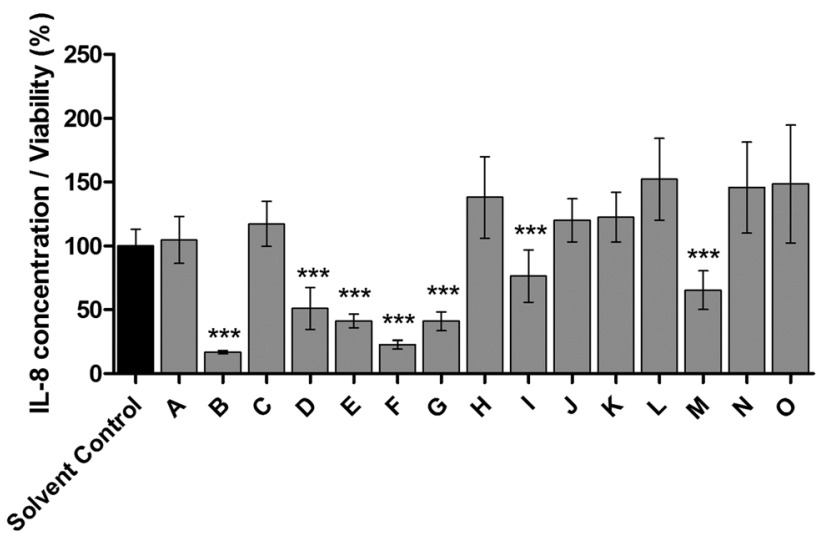

Fig. 4 Cinnamon fractions with anti-inflammatory effects in THP-1 monocytes. THP-1 monocytes were incubated with cinnamon fractions or respective solvent (acetonitrile/0.1\% formic acid in water), followed by stimulation of TLR4 with LPS-EB. IL-8 concentration was measured using ELISA, viability was measured using the Alamar Blue Assay and was normalized to viability of untreated cells. Data are displayed as IL-8 concentration divided by normalized viability and normalized to solvent-treated cells. Seven fractions showed TLR4 response below $77 \%$ : fraction $\mathrm{B}$ : $16.9 \%$ of solvent control, fraction $\mathrm{D}: 50.9 \%$, fraction $\mathrm{E}: 41.1 \%$, fraction $\mathrm{F}: 22.8 \%$, fraction $\mathrm{G}: 40.9 \%$, fraction I: $76.4 \%$ and fraction $M: 65.4 \%$. Data represent means \pm SD of 3 independent experiments (each with $n=3$ ); unpaired $t$-test (only anti-inflammatory effects marked): ${ }^{* *} p<0.0001$ compared to solvent control.

terns. Fraction M, the sole colored (yellowish) fraction, showed an (-)ESI-MS spectrum containing mass peaks at $\mathrm{m} / \mathrm{z} 255.23$, 283.26, 311.17, 329.23 and 529.46 (Fig. S1a†). The ion with $\mathrm{m} / \mathrm{z}$ 311.17 , as well as its product ion $\left(\mathrm{m} / z\right.$ 183.01) in the $\mathrm{MS}^{2}$ appeared also in the blank. Mass peaks at $\mathrm{m} / \mathrm{z} 255.23$ and $\mathrm{m} / \mathrm{z}$ 283.26 could be assigned to palmitic and stearic acid, ${ }^{37}$ in agreement with Mass Hunter (Agilent) formula calculator hits $\left(\mathrm{C}_{18} \mathrm{H}_{36} \mathrm{O}_{2}\right.$ and $\mathrm{C}_{16} \mathrm{H}_{3} \mathrm{O}_{2}$, respectively) and comparison to injected standards. The ion with $\mathrm{m} / \mathrm{z} 329.23$ and its product ion with $\mathrm{m} / \mathrm{z} 171.1$ indicated the presence of 9,10,13-trihydroxy-11-octadecenoic acid (9,10,13-TriHOME(11)), ${ }^{38,39}$ in line with Mass Hunter software hits $\left(\mathrm{C}_{18} \mathrm{H}_{34} \mathrm{O}_{5}\right)$. The molecular ion at $m / z 529.46$ was tentatively identified as octadecyl 3,5-di-tertbutyl-4-hydroxyhydrocinnamate $\left(\mathrm{C}_{35} \mathrm{H}_{62} \mathrm{O}_{3}\right),{ }^{40}$ which is known as a food antioxidant (Irganox 1076). Due to the chemical complexity of fractions B, D, E, F, G and I observed in HRMS, further separation of the compounds in a second chromatographic dimension would be needed to identify all active compounds.

As an alternative, a GC-MS method was developed to separate the compounds in the anti-inflammatory HPLC fractions. The method enabled us to identify the following compounds in the non-derivatized fractions: $p$-cymene and methyl salicylate (fraction B), 1-tetradecanol (myristyl alcohol) (fraction D), cinnamyl alcohol (fraction F) and cinnamaldehyde (fraction $\mathrm{M}$ ), while in the derivatized fractions, trimethyl silyl esters of only three compounds were observed: cinnamyl methyl ether, cinnamic and benzoic acids (fraction F) (Fig. S1b $\dagger$ ).

Where possible, the compounds tentatively identified in the cinnamon extract by HRMS and GC-MS (Table S2†) were purchased as pure reference compounds and tested for their antiinflammatory effects.

\section{Identification of trans-cinnamaldehyde and $p$-cymene as anti- inflammatory compounds}

Standard solutions of pure compounds which were identified in the anti-inflammatory fractions of cinnamon extract were tested in THP-1 monocytes for their effects on LPS-dependent IL-8 secretion in THP-1 cells (Fig. 5). trans-Cinnamaldehyde and $p$-cymene significantly reduced IL-8 secretion normalized to viability in LPS-stimulated THP-1 monocytes. Furthermore, trans-cinnamaldehyde and $p$-cymene were additionally tested in the HEK-TLR2/HEK-TLR4 comparative assay system on TLR4 specific antagonism (Fig. 6). A decrease of SEAP production normalized to viability was observed in LPS-stimulated HEK-TLR4 and Pam2CSK4-stimulated HEK-TLR2 cell lines after incubation with trans-cinnamaldehyde compared to the vehicle control (Fig. 6a). In both cell lines, comparable antiinflammatory effects $\left(10 \mu \mathrm{g} \mathrm{ml}^{-1}\right.$ trans-cinnamaldehyde) or a significantly lower inflammatory signal in HEK-TLR2 compared to HEK-TLR4 cells $\left(25 \mu \mathrm{g} \mathrm{ml}^{-1}\right.$ and $50 \mu \mathrm{g} \mathrm{ml}{ }^{-1}$ trans-cinnamaldehyde) were observed. In contrast, $p$-cymene did not reduce Pam2CSK4- or LPS-induced stimulation in HEK-TLR2 and HEK-TLR4 cells (Fig. 6b).

\section{Possible synergistic anti-inflammatory effects of compounds}

Therapeutic herbal extracts are highly complex matrices with beneficial health effects usually not based on a single compound. Often, the overall efficacy in a mixture is not only due to additive, but even to synergistic effects. ${ }^{41-43}$ Since trans-cinnamaldehyde showed the highest anti-inflammatory effect in THP-1 monocytes (Fig. 5), several identified compounds were separately pooled with trans-cinnamaldehyde to test for possible synergistic effects. Strong anti-inflammatory synergistic effects could be the possible explanation for the combined activity of trans-cinnamaldehyde with $p$-cymene, cinnamyl alcohol or cinnamic acid (Fig. 7). These effects were not only 


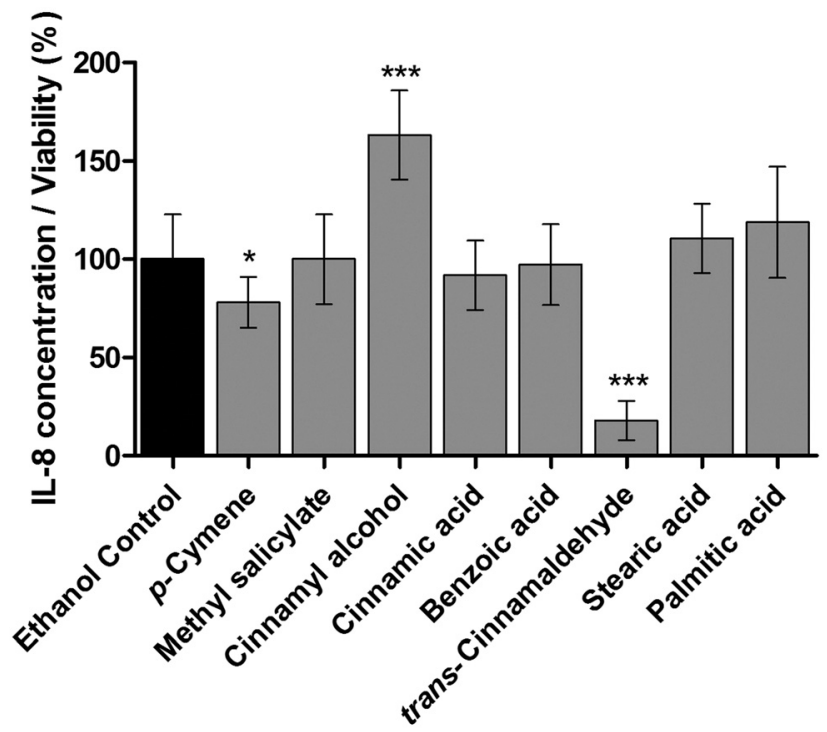

Fig. 5 Anti-inflammatory effects of select cinnamon compounds. THP-1 monocytes were incubated with $25 \mu \mathrm{g} \mathrm{ml} \mathrm{m}^{-1}$ of defined compounds present in cinnamon extract or vehicle (70\% aqueous ethanol), followed by stimulation of TLR4 with LPS-EB. IL- 8 secretion was measured using ELISA, viability was measured using the Alamar Blue Assay and was normalized to viability of untreated cells. Data are displayed as IL-8 concentration divided by normalized viability and normalized to vehicle-treated cells. Data represent means \pm SD of 3 independent experiments (each with $n=3$ ); unpaired $t$-test: ${ }^{*} p<0.05$; $* * * p<0.0001$ compared to solvent control.

significant compared to the vehicle control alone, but also when compared to the combination of trans-cinnamaldehyde with vehicle. Treatment with trans-cinnamaldehyde and ethanol control led to a reduction of IL-8 secretion to a level of $30.7 \%$ compared by treatment with ethanol alone. Combined treatment of trans-cinnamaldehyde with cinnamic acid further reduced IL-8 secretion to a level of $13.4 \%$, a combination of trans-cinnamaldehyde with $p$-cymene to $11.2 \%$ and the combination of trans-cinnamaldehyde with cinnamyl alcohol to $3.2 \%$.

\section{Effects on phosphorylation of TLR signaling pathway molecules}

Possible mechanisms by which cinnamon extract and its active compounds, trans-cinnamaldehyde and $p$-cymene mitigate the LPS-induced production of pro-inflammatory cytokines in THP-1 monocytes, were investigated by the phosphorylation ratio of the molecules Akt, IкB $\alpha$ and $\mathrm{p} 38$.

Only slight changes in protein level of Akt were observed in THP-1 monocytes after different treatments (Fig. 8a), whereas Akt phosphorylation (Fig. 8b) was strongly mitigated after treatment with cinnamon extract, trans-cinnamaldehyde and $p$-cymene. The same effects were observed for the relative ratio of phospho-Akt to Akt protein level (Fig. 8c). Compared to negative control, IкB $\alpha$ protein level was reduced in THP-1 monocytes after LPS treatment (Fig. 9a). This reduction was mitigated after treatment with cinnamon extract, trans-cin-
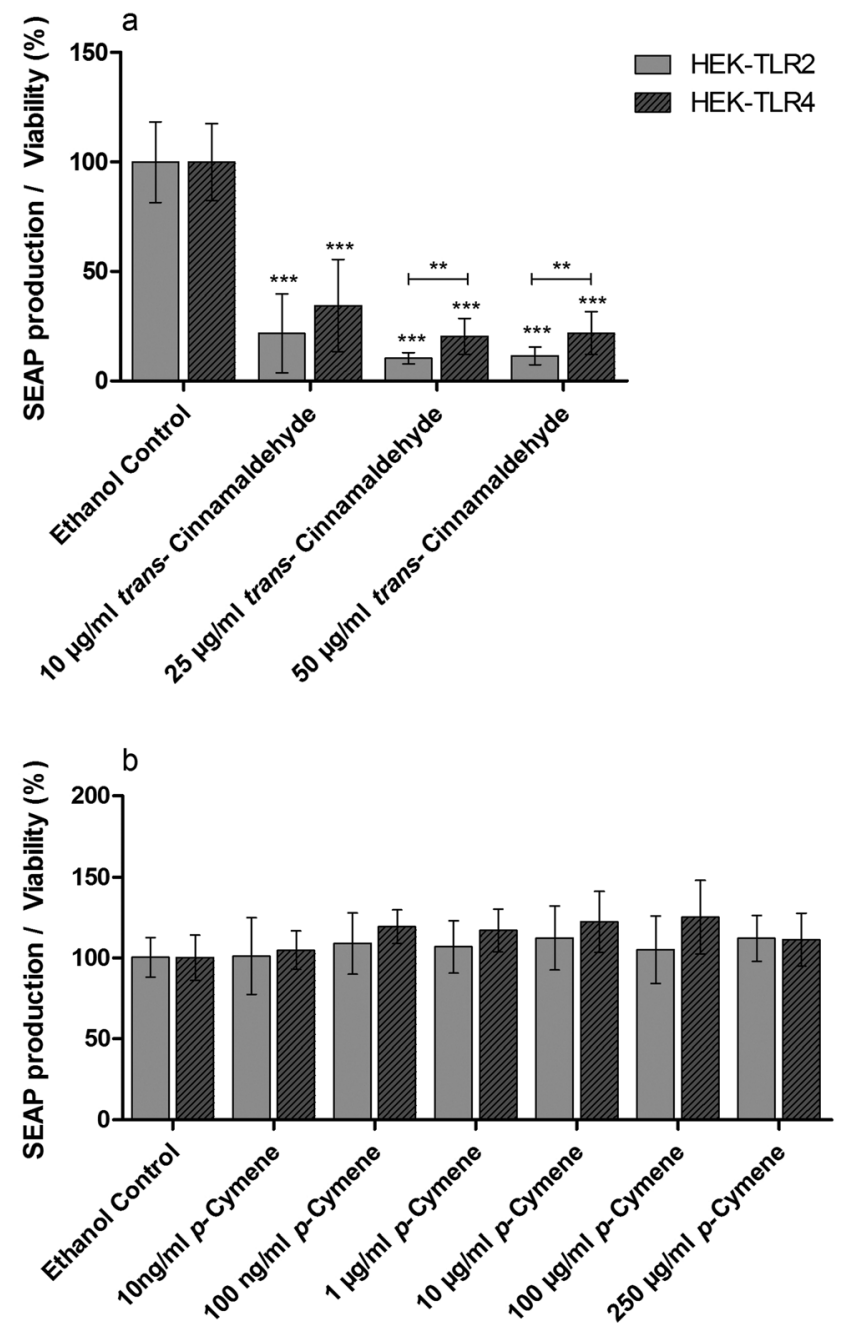

Fig. 6 Anti-inflammatory effects of trans-cinnamaldehyde and $p$-cymene in HEK-TLR2 and HEK-TLR4 cells. HEK-TLR2 and HEK-TLR4 cells were incubated with trans-cinnamaldehyde, $p$-cymene or vehicle (70\% aqueous ethanol), followed by stimulation of TLR2 with Pam2CSK4 (HEK-TLR2 cells) or TLR4 with LPS-EB Ultrapure (HEK-TLR4 cells). TLR2 or TLR4 receptor response was determined measuring NF- $\kappa \mathrm{B}-$ and AP-1-dependent SEAP production, viability was measured using the Alamar Blue Assay and was normalized to viability of untreated cells. Data are displayed as receptor activity divided by normalized viability. Data represent means \pm SD $(n=5)$; unpaired $t$-test: ${ }^{* *} p<0.01$ comparison of both cell lines; ${ }^{* *} p<0.0001$ compared to ethanol.

namaldehyde and $p$-cymene, which was significant for treatment with trans-cinnamaldehyde. Treatment of LPS-stimulated THP-1 monocytes with cinnamon extract, trans-cinnamaldehyde and $p$-cymene resulted in a mitigation of IкB $\alpha$ phosphorylation, which was significant for the treatment with cinnamon extract and trans-cinnamaldehyde compared to solvent control (Fig. 9b). Significant attenuation was observed for all three treatments for the relative ratio of phospho-IкB $\alpha$ to IкB $\alpha$ protein (Fig. 9c). After the different treatments, only slight changes in p38 protein were observed (Fig. 10a). Treatment with cinnamon extract and $p$-cymene resulted in a small but significant increase of p38 phosphorylation (Fig. 10b). A sig- 


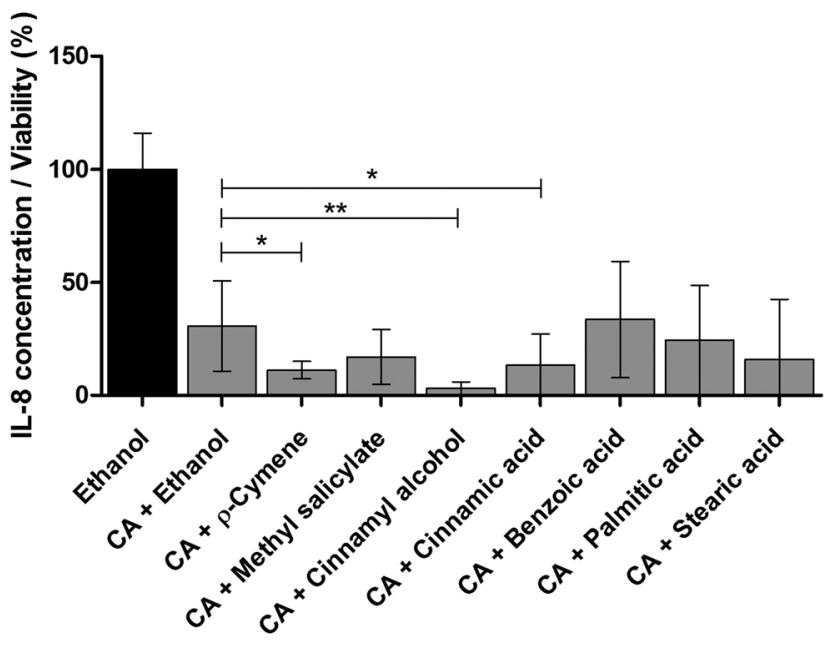

Fig. 7 Synergistic anti-inflammatory effects of cinnamon extract compounds in THP-1 monocytes. THP-1 monocytes were incubated with combination of $25 \mu \mathrm{g} \mathrm{ml}^{-1}$ trans-cinnamaldehyde (CA) and $25 \mathrm{\mu g} \mathrm{ml}^{-1}$ additional defined compounds present in cinnamon extract or vehicle ( $70 \%$ aqueous ethanol), followed by stimulation of TLR4 with LPS-EB. IL- 8 secretion was measured using ELISA, viability was measured using the Alamar Blue Assay and was normalized to viability of untreated cells. Data are displayed as IL- 8 concentration divided by normalized viability and normalized to vehicle-treated cells. Data represent means \pm SD $(n \geq$ 6); unpaired $t$-test: ${ }^{* \star *} p<0.0001$ all treatments compared to ethanol control (not marked in graph); ${ }^{*} p<0.05,{ }^{* *} p<0.005$ compared to incubation with $\mathrm{CA}+$ ethanol.

nificant increase was also observed for the relative ratio of p-p38 to p38 protein level after $p$-cymene treatment (Fig. 10c).

\section{Discussion}

The anti-inflammatory effects observed for cinnamon extract in THP-1 monocytes are in line with those described before where pre-incubation of murine RAW macrophages with $0.1 \%$ to $0.4 \%$ cinnamon extract lead to a decreased LPS-induced expression of TNF- $\alpha$ mRNA. ${ }^{16}$ A comparable dose of ethanolic cinnamon extract $\left(4.5 \mathrm{ml} \mathrm{kg} \mathrm{kg}^{-1}\right.$ body weight per day) also showed inhibitory effects in a mouse model of colitis. ${ }^{17}$ Furthermore, cinnamon extract apparently interferes with the downstream signaling pathways common for both TLR2 and TLR4, such as the central NF- $\mathrm{KB} / \mathrm{AP}-1$ signaling, which was shown by comparable suppression on the HEK-TLR2 and HEK-TLR4 assay systems.

To identify all major compounds responsible for specific anti-inflammatory effects, bioassay-guided fractionation of cinnamon extract was performed. In the first dimension HPLC was used, followed by GC in the second dimension. Several compounds were identified in the determined active fractions using the GC-MS method and HRMS. Bioassay-guided fractionation is a well-established approach for untargeted, but focused screening of active compounds in complex matrices. ${ }^{44-48}$ From the identified compounds (Table $\mathrm{S} 2 \dagger$ ), p-cymene, cinnamyl alcohol, cinnamic acid and cinnamalde- hyde are present in Cinnamomum verum extract, with the latter as major active principle. ${ }^{15,24,49,50}$ To the best of our knowledge, the other compounds shown in Table $52 \uparrow$ were not reported to be present in cinnamon extract so far. Compounds in commercial extracts may undergo different chemical reactions (e.g. degradation, oxidation, and polymerization) and thus impose some issues during chemical analysis. Sometimes even unreliable data regarding the naturally present compounds can be obtained in the case some chemical reactions have already occurred. If some compounds in the commercially available extracts degrade with time, degradants may start a new degradation cascade. This can happen for example, after degradation of the naturally present antioxidants. Further, polymerization processes (oligomers and polymers) could occur by aging of the formulation. Commercial extracts might be enriched with additional compounds like antioxidants, colorants or preservatives. One should also be aware of the compatibility issues between the naturally occurring compounds in the extracts and the excipients, as degradation products may arise from these reactions as well. ${ }^{51}$ These effects might impose additional problems with analysis of the commercial plant extract. However, cinnamon tincture is a simple formulation and no compatibility issues with excipients are expected. Moreover, our cinnamon extract showed to be stable during the time of the study, since HPLC chromatograms were always repeatable with no additional peaks appearing during the storage period of at least one year and within the shelf-life of the extract. Moreover, the use of the commercial extract in our experiments reflects the practical source and common supply.

The observed decrease of LPS-induced IL-8 secretion in THP-1 monocytes by $p$-cymene in vitro complements reports on its anti-inflammatory effects in vivo, e.g. in mouse models of elastase-induced emphysema, ${ }^{52}$ carrageenan-induced peritonitis, ${ }^{53}$ and LPS-induced acute lung injury. ${ }^{54}$ In addition, we could also confirm cinnamaldehyde-dependent anti-inflammatory effects. $^{24,27,55}$ Besides the various beneficial health effects, cinnamaldehyde was also reported to directly suppress TLR4 activation by inhibition of receptor dimerization. ${ }^{29}$ Furthermore, the disruption of TLR4-MD-2 heterodimers by formation of covalent adducts has been proposed as main mechanism of action for cinnamaldehyde. ${ }^{11}$ By testing whole cinnamon extract, the cinnamaldehyde's antagonistic effects for TLR4 were not confirmed in our test system. Therefore, trans-cinnamaldehyde was additionally tested in the HEK-TLR2/HEK-TLR4 comparative assay system for TLR4 specific antagonism. The significant decrease of the inflammatory signal in HEK-TLR2 and HEK-TLR4 cells indicates an involvement of trans-cinnamaldehyde in both TLR2 and TLR4 signaling pathways, indicating that its mode of action goes beyond a sole TLR4 antagonism and the reported suppression of TLR4 receptor dimerization. Interestingly, a tendency was observed that trans-cinnamaldehyde acts as a slightly stronger TLR2- than TLR4-antagonist. Nevertheless, compared to LPStreated cells, trans-cinnamaldehyde resulted in a strong significant reduction of SEAP production in both, TLR2- and TLR4- 

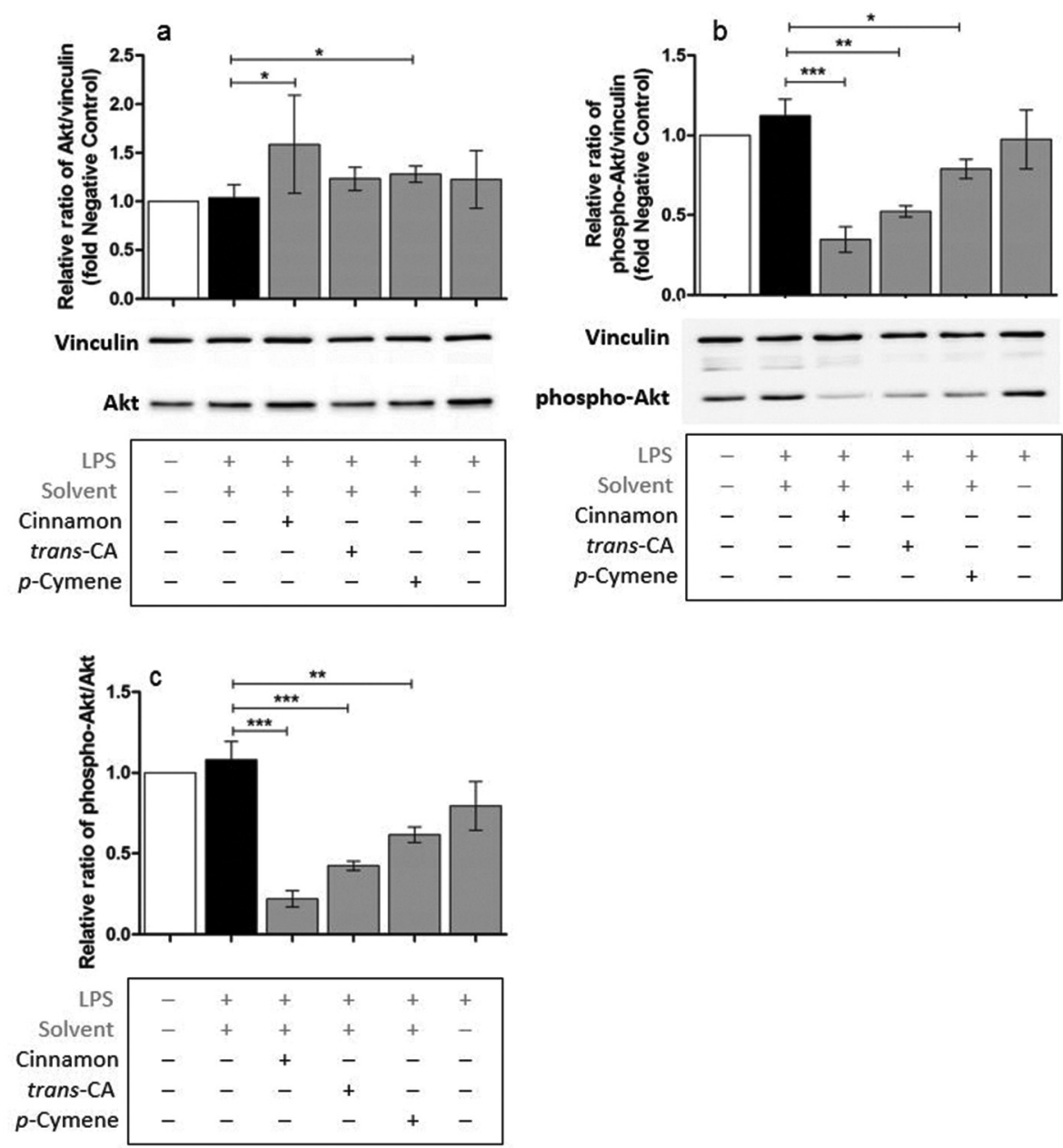

Fig. 8 Influence of cinnamon extract, trans-cinnamaldehyde or p-cymene on Akt phosphorylation. THP-1 monocytes were incubated with cinnamon extract, trans-cinnamaldehyde or p-cymene, followed by stimulation with LPS-EB. Akt and phospho-Akt protein level were determined using Western Blot analysis. Data are displayed as relative protein expression normalized to vinculin loading control and normalized to the negative control (untreated cells). a: Akt protein level normalized to vinculin, b: phosphor-Akt protein level normalized to vinculin, c: phosphor-Akt protein level normalized to Akt protein level. Data represent means \pm SD $(n=3)$; unpaired $t$-test: ${ }^{* * *} p<0.001,{ }^{* *} p<0.005,{ }^{*} p<0.05$ compared to solvent control. trans-CA: trans-cinnamaldehyde.

transfected, reporter cells. Furthermore, $p$-cymene was tested in the same assay system for TLR4 specific antagonism. We could not demonstrate $p$-cymene mediated attenuation of Pam2CSK4- or LPS-induced SEAP production in HEK-TLR2 and HEK-TLR4 cells. Since both cell lines were co-transfected with human TLR2 or TLR4 receptors and do not exhibit all cofactors of other TLR2/TLR4-related pathways, $p$-cymene may still be active by interfering with pathways not present in these cell lines. We also demonstrated that trans-cinnamaldehyde might possess synergistic effects when combined with $p$-cymene, cinnamyl alcohol and cinnamic acid. Nevertheless, the actual ratios of the compounds within the tested cinnamon bark extract might differ from the 1:1 ratio used for the demonstration of possible synergistic effects. In vivo, cinnamaldehyde and cinnamyl alcohol can transform into one another depending on redox conditions. In addition, cinnamaldehyde can be oxidized to cinnamic acid. ${ }^{27}$ One hypothesis for the synergistic effects of cinnamaldehyde in combination with cinnamic acid and cinnamyl alcohol in our assay system could be that during the assay, a (partial) transformation takes place. A counter-argument for this hypothesis is the proinflammatory effect of cinnamyl alcohol observed in our assay when given alone. It is very unlikely that the $\mathrm{pH}$ of the system (the $\mathrm{p} K_{\mathrm{a}}$ value for cis-cinnamic acid is 3.88 and for trans-cinnamic acid is 4.44) is responsible for the synergistic effects when combined with cinnamaldehyde, since benzoic acid (with comparable $\mathrm{p} K_{\mathrm{a}}$ value of 4.204$)^{56}$ did not show any synergistic effect when combined with trans-cinnamaldehyde. Another hypothesis for the synergistic effects of trans-cinnamaldehyde with $p$-cymene, cinnamyl alcohol or cinnamic acid could be the possible stabilizing effects of the compounds on the aldehyde functional group of trans-cinnamaldehyde. Here, our results provide a first mechanistic basis for the empirical observation that the isolated active compounds of herbal 

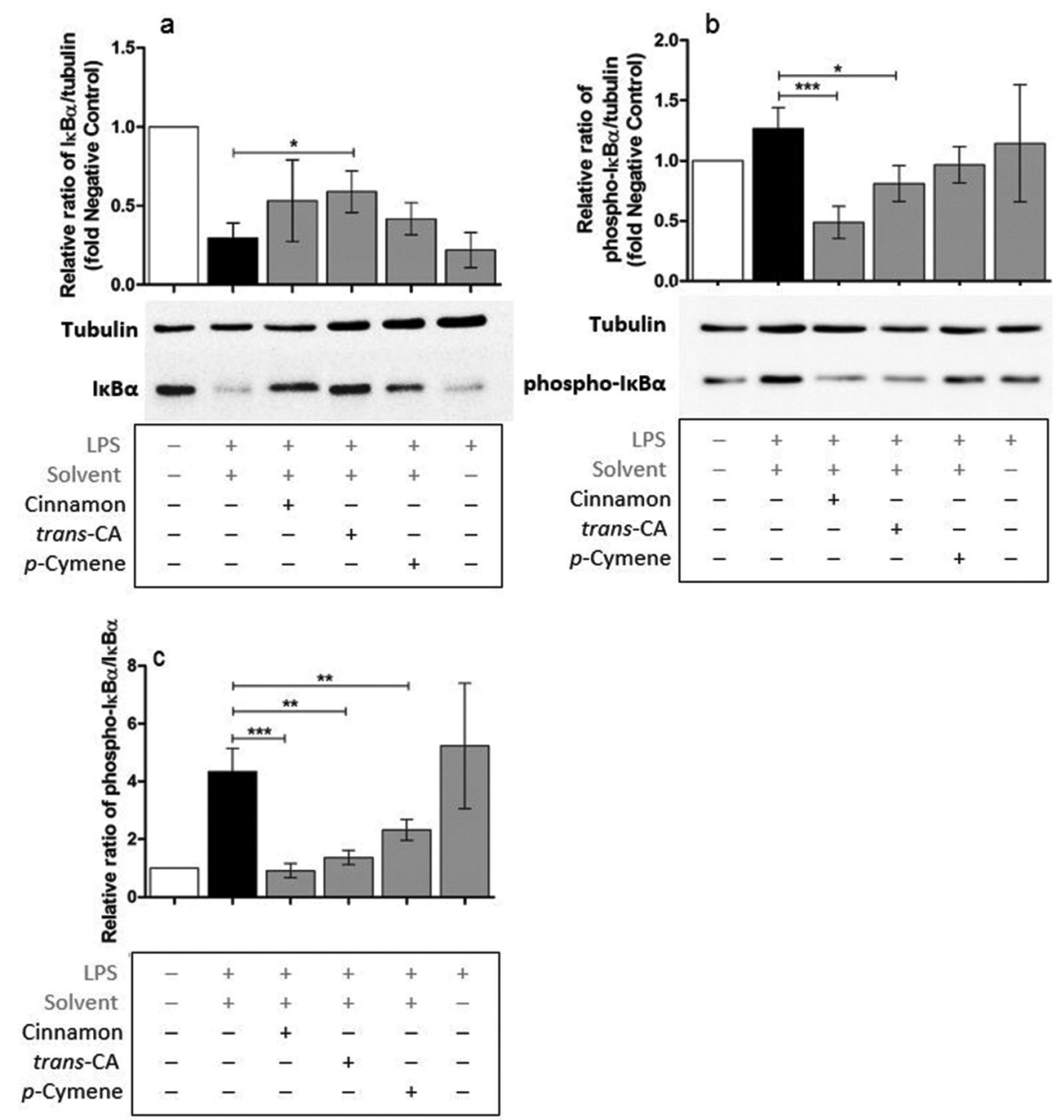

Fig. 9 Influence of cinnamon extract, trans-cinnamaldehyde or $p$-cymene on IKB $\alpha$ phosphorylation. THP-1 monocytes were incubated with cinnamon extract, trans-cinnamaldehyde or $p$-cymene, followed by stimulation with LPS EB. IKB $\alpha$ and phospho-IKB $\alpha$ protein level were determined using Western Blot analysis. Data are displayed as relative protein expression normalized to tubulin loading control and normalized to the negative control

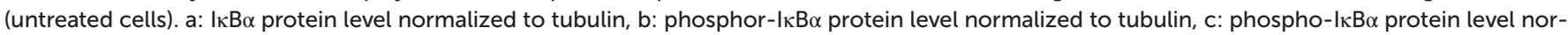
malized to $\mathrm{I} \kappa \mathrm{B} \alpha$ protein level. Data represent means $\pm \mathrm{SD}(n=3)$; unpaired $t$-test: ${ }^{* \star *} p<0.001,{ }^{* \star} p<0.001,{ }^{*} p<0.05$ compared to solvent control. trans-CA: trans-cinnamaldehyde.

medications often do not display the efficacy of complex herbal extracts. ${ }^{41-43}$ Still, the strong combined effects of transcinnamaldehyde with $p$-cymene, cinnamyl alcohol and cinnamic acid raise the question as to the underlying mechanisms as well as to which extent the in vitro effects reported in this study are transferable to in vivo systems. Therefore, further studies, especially using specific inhibitors and activators of the TLR4 and other signaling pathways, should help to clarify the exact responsible mechanisms.

Based on the findings of the phosphorylation experiments, it can be concluded that cinnamon extract, trans-cinnamaldehyde and $p$-cymene inhibit the pro-inflammatory signal transduction of early TLR2 and TLR4 signaling events. After TLR4 stimulation via the phosphatidylinositol 3-kinase (PI3K) pathway, Akt is phosphorylated and regulates the transcriptional activity of NF- $\kappa \mathrm{B}$ by the induction of I $\mathrm{IB} \alpha$ phosphorylation and degradation. ${ }^{3,4}$ Furthermore, phosphorylation of the
MAP kinase $\mathrm{p} 38$, leads primarily to the activation of AP-1, but also of NF- $\mathrm{BB}$, contributing to the expression of several proinflammatory cytokines, e.g. IL-1, IL-6, IL-8 and TNF- $\alpha .{ }^{4,57}$ Since a rather short incubation time for LPS was chosen $(1 \mathrm{~h}$ treatment), no significant increase of phospho-Akt activation was observed in the performed experiments. Nevertheless, in line with our findings, cinnamon extract and the cinnamaldehyde derivative 4-hydroxycinnamaldehyde-galactosamine were shown to inhibit the phosphorylation of Akt in different stimu-

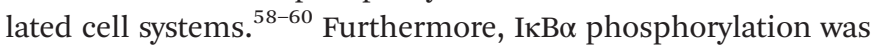
significantly reduced in the IL-10-/- colitis mouse model after incubation with cinnamon extract, ${ }^{17}$ in a mouse model of myocarditis after incubation with $\alpha$-bromo-4-chlorocinnamaldehyde $^{61}$ and in LPS-induced murine inflammation after incubation with $p$-cymene, ${ }^{54}$ which is in accord with a significant decrease of phospho-IкB $\alpha$ protein level in myeloid cells as found by us. In contrast to our data, mice treated with cinna- 

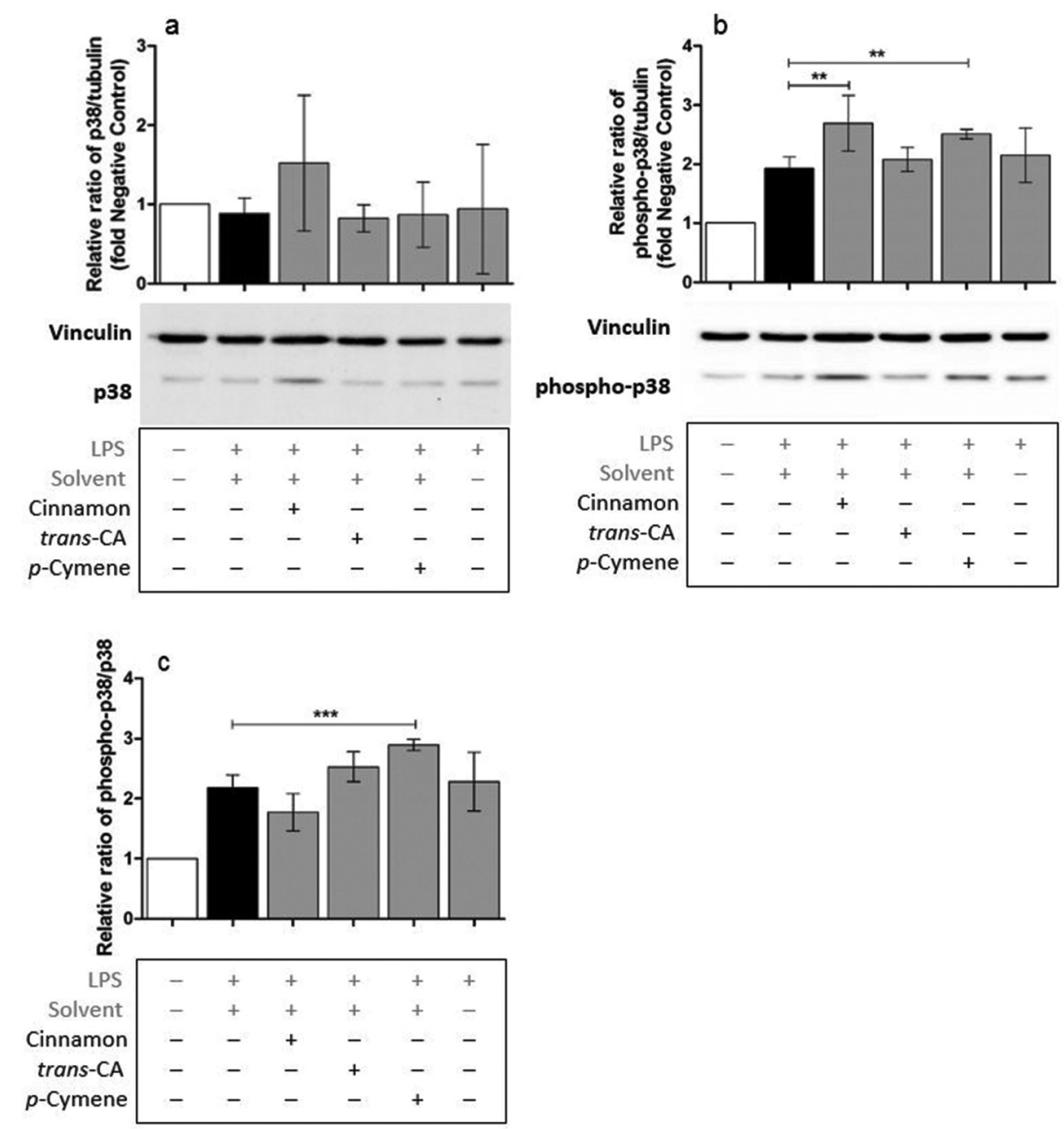

Fig. 10 Influence of cinnamon extract, trans-cinnamaldehyde or $p$-cymene on $\mathrm{p} 38$ phosphorylation. THP-1 monocytes were incubated with cinnamon extract, trans-cinnamaldehyde or $p$-cymene, followed by stimulation with LPS EB. p38 and phospho-p38 protein level were determined using Western Blot analysis. Data are displayed as relative protein expression normalized to vinculin loading control and normalized to the negative control (untreated cells). a: p38 protein level normalized to vinculin, b: phospho-p38 protein level normalized to vinculin, c: phosphor-p38 protein level normalized to p38 protein level. Data represent means \pm SD $(n=3)$; unpaired $t$-test: ${ }^{* \star *} p<0.005,{ }^{*} p<0.001$, compared to solvent control. trans-CA: trans-cinnamaldehyde.

maldehyde without further stimulation showed a significant increase of Akt phosphorylation. ${ }^{62}$ This controversy effect might be due to the lack of further stimulation. Contrarious to our data, cinnamon extract in IgE-stimulated human intestinal mast cells was reported to attenuate p38 phosphorylation ${ }^{63}$ and p38 phosphorylation was significantly reduced in THP-1derived macrophages after treatment with trans-cinnamaldhyde, ${ }^{28}$ whereas cinnamaldehyde was shown to induce phosphorylation of p38 in murine inguinal adipocytes. ${ }^{64}$ In a LPSinduced acute lung injury mouse model, $p$-cymene revealed a dose-dependent significant mitigation of p38 phosphorylation. ${ }^{54}$ Interestingly, the reported decrease of phospho-IкB $\alpha /$ IкB $\alpha$ protein ratio after $p$-cymene treatment in the same study has been in line with our data. Whether the disagreement on the influences on p38 phosphorylation might be due to the different interactions of the MAP Kinase in diverse cell types, a lack of transferability between the performed cell culture- based assays and mouse models, or if rather short incubation times ( $2 \mathrm{~h}$ incubation, followed by $1 \mathrm{~h}$ LPS stimulation) that we chose in our experiments or different concentrations might reveal a contrary result would be interesting for further analysis.

Other groups demonstrated beneficial effects for comparable doses of cinnamon extract, e.g., in mouse models of alcoholinduced liver steatosis. ${ }^{16}$ Furthermore, 1-6 g cinnamon bark showed beneficial effects in patients with type 2 diabetes, demonstrating a safe usage without major toxic effects. ${ }^{65,66}$ Our data suggest that cinnamon extract might not only play an important role in diabetes, but also in other inflammatory diseases.

A deeper understanding of the underlying mechanisms is necessary to disclose novel strategies for the treatment of inflammation. We show that cinnamon extract, its active compounds trans-cinnamaldehyde and $p$-cymene or combinations increase potency of central active compounds opening up novel treatment strategy for diverse inflammatory diseases. 


\section{Abbreviations}

$(+) \quad$ Positive ion mode

(-) Negative ion mode

AP-1 Activator protein 1

Akt Protein kinase B

BCA Bicinchoninic acid

DAD Diode array detector

DMEM Dulbecco's Modified Eagle Medium

EFSA European food safety authority

ESI Electrospray ionization

ELISA Enzyme-linked immunosorbent assay

EAE

FCS

GC

HEK-TLR2

HEK-TLR4

HPLC

HRMS

MAP

$\mathrm{I} \kappa \mathrm{B} \alpha$

IL

LPS

MS

NO

NF- $\kappa \mathrm{B}$

Experimental allergic encephalomyelitis

Fetal calf serum

Gas chromatography

HEK-Blue hTLR2 cell line

HEK-Blue hTLR4 cell line

High-performance liquid chromatography

High-resolution mass spectrometry

Mitogen-activated protein

NF- $\kappa$ B inhibitor alpha

Interleukin

Lipopolysaccharide

Mass spectrometry

Nitric oxide

Pam2CSK4 $S$-[2,3-Bis(palmitoyloxy)-(2RS)-propyl]-[R]-cysteinyl$[S]$-seryl- $[S]$-lysyl- $[S]$-lysyl- $[S]$-lysyl- $[S]$-lysine

PI3K Phosphatidylinositol 3-kinase

PPAR $\gamma$ Peroxisome proliferator-activated receptor gamma

RNS Reactive nitrogen species

ROS Reactive oxygen species

SDS-PAGE Sodium dodecyl sulfate-Polyacrylamide gel electrophoresis

SEAP Secreted embryonic alkaline phosphatase

SILMAS Trimethylsilyl methallylsulfinate

TDI Tolerable daily intake

TLR Toll-like receptor

TNF Tumor necrosis factor

TBS-T Tris-buffered saline with Tween-20

Q-TOF Quadrupole-time-of-flight

\section{Conflicts of interest}

There are no conflicts to declare.

\section{Acknowledgements}

The authors would like to acknowledge the inspiring discussions with the members of Mainz Program for Chemical Allergology (MPCA). They would also like to acknowledge the support from the Max Planck Graduate Center with the Johannes Gutenberg University Mainz (MPGC) and the bilateral project financed by the Slovenian research agency (ARRS) BI-DE-17-19-14 and the Deutscher Akademischer Austauschdienst (DAAD) Project ID: 57366807. Open Access funding provided by the Max Planck Society.

\section{References}

1 K. Lucas and M. Maes, Role of the Toll Like receptor (TLR) radical cycle in chronic inflammation: possible treatments targeting the TLR4 pathway, Mol. Neurobiol., 2013, 48(1), 190-204, DOI: 10.1007/S12035-013-8425-7.

2 D. Walsh, J. McCarthy, C. O'Driscoll and S. Melgar, Pattern recognition receptors - Molecular orchestrators of inflammation in inflammatory bowel disease, Cytokine Growth Factor Rev., 2013, 24(2), 91-104, DOI: 10.1016/j. cytogfr.2012.09.003.

3 D. Bai, L. Ueno and P. K. Vogt, Akt-mediated regulation of NFkappaB and the essentialness of NFkappaB for the oncogenicity of PI3K and Akt, Int. J. Cancer, 2009, 125(12), 28632870, DOI: 10.1002/ijc.24748.

4 Y. Yang, J. Lv, S. Jiang, Z. Ma, D. Wang, W. Hu, C. Deng, C. Fan, S. Di, Y. Sun and W. Yi, The emerging role of Tolllike receptor 4 in myocardial inflammation, Cell Death Dis., 2016, 7, e2234, DOI: 10.1038/cddis.2016.140.

5 K. W. McGrath, N. Icitovic, H. A. Boushey, S. C. Lazarus, E. R. Sutherland, V. M. Chinchilli and J. V. Fahy, A large subgroup of mild-to-moderate asthma is persistently noneosinophilic, Am. J. Respir. Crit. Care Med., 2012, 185(6), 612-619, DOI: 10.1164/rccm.201109-1640OC.

6 D. Schuppan and Y. O. Kim, Evolving therapies for liver fibrosis, J. Clin. Invest., 2013, 123(5), 1887-1901, DOI: 10.1172/JCI66028.

7 R. Holmdahl, V. Malmström and H. Burkhardt, Autoimmune priming, tissue attack and chronic inflammation - the three stages of rheumatoid arthritis, Eur. J. Immunol., 2014, 44(6), 1593-1599, DOI: 10.1002/ eji.201444486.

8 J. W. McAlees, G. S. Whitehead, I. T. Harley, M. Cappelletti, C. L. Rewerts, A. M. Holdcroft, S. Divanovic, M. Wills-Karp, F. D. Finkelman, C. L. Karp and D. N. Cook, Distinct Tlr4expressing cell compartments control neutrophilic and eosinophilic airway inflammation, Mucosal Immunol., 2015, 8(4), 863-873, DOI: 10.1038/mi.2014.117.

9 M. Yamada, T. Ichikawa, M. Ii, M. Sunamoto, K. Itoh, N. Tamura and T. Kitazaki, Discovery of novel and potent small-molecule inhibitors of $\mathrm{NO}$ and cytokine production as antisepsis agents: synthesis and biological activity of alkyl 6-(N-substituted sulfamoyl)cyclohex-1-ene-1-carboxylate, J. Med. Chem., 2005, 48(23), 7457-7467.

10 M. Tidswell, W. Tillis, S. P. Larosa, M. Lynn, A. E. Wittek, R. Kao, J. Wheeler, J. Gogate and S. M. Opal, Phase 2 trial of eritoran tetrasodium (E5564), a toll-like receptor 4 antagonist, in patients with severe sepsis, Crit. Care Med., 2010, 38(1), 72-83, DOI: 10.1097/CCM.0b013e3181b07b78. 
11 F. Peri and V. Calabrese, Toll-like receptor 4 (TLR4) modulation by synthetic and natural compounds: an update, J. Med. Chem., 2014, 57(9), 3612-3622, DOI: 10.1021/ jm401006s.

12 H. S. Youn, J. Y. Lee, S. I. Saitoh, K. Miyake, K. W. Kang, Y. J. Choi and D. H. Hwang, Suppression of MyD88- and TRIF-dependent signaling pathways of Toll-like receptor by (-)-epigallocatechin-3-gallate, a polyphenol component of green tea, Biochem. Pharmacol., 2006, 72(7), 850-859.

13 S. J. Park, M. Y. Lee, B. S. Son and H. S. Youn, TBK1-targeted suppression of TRIF-dependent signaling pathway of Tolllike receptors by 6-shogaol, an active component of ginger, Biosci., Biotechnol., Biochem., 2009, 73(7), 1474-1478.

14 D. S. Chahal, R. K. Sivamani, R. R. Isseroff and M. R. Dasu, Plant-based modulation of Toll-like receptors: an emerging therapeutic model, Phytother. Res., 2013, 27(10), 1423-1438, DOI: $10.1002 /$ ptr.4886.

15 G. K. Jayaprakasha and L. J. Rao, Chemistry, biogenesis, and biological activities of Cinnamomum zeylanicum, Crit. Rev. Food Sci. Nutr., 2011, 51(6), 547-562, DOI: 10.1080/ 10408391003699550.

16 G. Kanuri, S. Weber, V. Volynets, A. Spruss, S. C. Bischoff and I. Bergheim, Cinnamon extract protects against acute alcohol-induced liver steatosis in mice, J. Nutr., 2009, 139(3), 482-487, DOI: 10.3945/jn.108.100495.

17 Y. Hagenlocher, A. Hösel, S. C. Bischoff and A. Lorentz, Cinnamon extract reduces symptoms, inflammatory mediators and mast cell markers in murine IL-10(-/-) colitis, J. Nutr. Biochem., 2016, 30, 85-92, DOI: 10.1016/j. jnutbio.2015.11.015.

18 Y. Hagenlocher, S. Satzinger, M. Civelek, K. Feilhauer, J. Köninger, S. C. Bischoff and A. Lorentz, Cinnamon reduces inflammatory response in intestinal fibroblasts in vitro and in colitis in vivo leading to decreased fibrosis, Mol. Nutr. Food Res., 2017, 61(9), 1601085, DOI: 10.1002/ mnfr.201601085.

19 X. Sheng, Y. Zhang, Z. Gong, C. Huang and Y. Q. Zang, Improved Insulin Resistance and Lipid Metabolism by Cinnamon Extract through Activation of Peroxisome Proliferator-Activated Receptors, PPAR Res., 2008, 2008, 581348, DOI: 10.1155/2008/581348.

20 M. Hariri and R. Ghiasvand, Cinnamon and Chronic Diseases, Adv. Exp. Med. Biol., 2016, 929, 1-24.

21 S. Mondal and K. Pahan, Cinnamon ameliorates experimental allergic encephalomyelitis in mice via regulatory $\mathrm{T}$ cells: implications for multiple sclerosis therapy, PLoS One, 2015, 10(1), e0116566, DOI: 10.1371/journal.pone.0116566.

22 S. C. Ho, K. S. Chang and P. W. Chang, Inhibition of neuroinflammation by cinnamon and its main components, Food Chem., 2013, 138(4), 2275-2282, DOI: 10.1016/j. foodchem.2012.12.020.

23 D. Gunawardena, S. Govindaraghavan and G. Münch, Antiinflammatory properties of cinnamon polyphenols and their monomeric precursors, in Polyphenols in Human Health and Disease, ed. R.R Watson, V.R Preedy and S. Zibadi, Elsevier, Amsterdam, Boston, Heidelberg,
London, New York, Oxford, Paris, San Diego, San Francisco, Singapore, Sydney, Tokyo, 2014, vol. 1, pp. 30:409-30:425.

24 D. Gunawardena, N. Karunaweera, S. Lee, F. van Der Kooy, D. G. Harman, R. Raju, L. Bennett, E. Gyengesi, N. J. Sucher and G. Münch, Anti-inflammatory activity of cinnamon (C. zeylanicum, and C. cassia) extracts-identification of E-cinnamaldehyde and o-methoxy cinnamaldehyde as the most potent bioactive compounds, Food Funct., 2015, 6(3), 910-919, DOI: 10.1039/c4fo00680a.

25 Y. Hagenlocher, K. Kiessling, M. Schäffer, S. C. Bischoff and A. Lorentz, Cinnamaldehyde is the main mediator of cinnamon extract in mast cell inhibition, Eur. J. Nutr., 2015, 54(8), 1297-1309, DOI: 10.1007/s00394-014-0810-0.

26 R. de Cássia da Silveira E Sá, L. N. Andrade, R. Dos Reis Barreto de Oliveira and D. P. de Sousa, A review on antiinflammatory activity of phenylpropanoids found in essential oils, Molecules, 2014, 19(2), 1459-1480, DOI: 10.3390/ molecules19021459.

27 R. Zhu, H. Liu, C. Liu, L. Wang, R. Ma, B. Chen, L. Li, J. Niu, M. Fu, D. Zhang and S. Gao, Cinnamaldehyde in diabetes: A review of pharmacology, pharmacokinetics and safety, Pharmacol. Res., 2017, 122, 78-89, DOI: 10.1016/j. phrs.2017.05.019.

28 J. Chung, S. Kim, H. A. Lee, M. H. Park, S. Y. Kim, Y. R. Song and H. S. Na, Trans-cinnamic aldehyde inhibit Aggregatibacter actinomycetemcomitansinduced inflammation THP-1-derived macrophages via autophagy activation, J. Periodontol., 2018, 89(10), 12621271, DOI: 10.1002/JPER.17-0727.

29 H. S. Youn, J. K. Lee, Y. J. Choi, S. I. Saitoh, K. Miyake, D. H. Hwang and J. Y. Lee, Cinnamaldehyde suppresses toll-like receptor 4 activation mediated through the inhibition of receptor oligomerization, Biochem. Pharmacol., 2008, 75(2), 494-502.

30 A. A. Hosni, A. A. Abdel-Moneim, E. S. Abdel-Reheim, S. M. Mohamed and H. Helmy, Cinnamaldehyde potentially attenuates gestational hyperglycemia in rats through modulation of PPAR $\gamma$, proinflammatory cytokines and oxidative stress, Biomed. Pharmacother., 2017, 88, 52-60, DOI: 10.1016/j.biopha.2017.01.054.

31 K. Abraham, M. Pfister, F. Wöhrlin and A. Lampen, Relative bioavailability of coumarin from cinnamon and cinnamon-containing foods compared to isolated coumarin: a four-way crossover study in human volunteers, Mol. Nutr. Food Res., 2011, 55(4), 644-653, DOI: 10.1002/ mnfr.201000394.

32 T.Ø Fotland, J. E. Paulsen, T. Sanner, J. Alexander and T. Husøy, Risk assessment of coumarin using the bench mark dose (BMD) approach: children in Norway which regularly eat oatmeal porridge with cinnamon may exceed the TDI for coumarin with several folds, Food Chem. Toxicol., 2012, 50(3-4), 903-912, DOI: 10.1016/j. fct.2011.12.005.

33 F. Woehrlin, H. Fry, K. Abraham and A. Preiss-Weigert, Quantification of flavoring constituents in cinnamon: high 
variation of coumarin in cassia bark from the German retail market and in authentic samples from indonesia, J. Agric. Food Chem., 2010, 58(19), 10568-10575, DOI: 10.1021/jf102112p.

34 D. H. Kim, C. H. Kim, M. S. Kim, J. Y. Kim, K. J. Jung, J. H. Chung, W. G. An, J. W. Lee, B. P. Yu and H. Y. Chung,

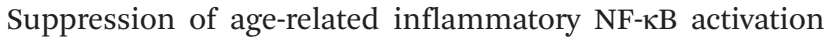
by cinnamaldehyde, Biogerontology, 2007, 8(5), 545554.

35 L. K. Chao, K. F. Hua, H. Y. Hsu, S. S. Cheng, I. F. Lin, C. J. Chen, S. T. Chen and S. T. Chang, Cinnamaldehyde inhibits pro-inflammatory cytokines secretion from monocytes/macrophages through suppression of intracellular signaling, Food Chem. Toxicol., 2008, 46(1), 220-231.

36 G. Szabo, A. Dolganiuc, Q. Dai and S. B. Pruett, TLR4, ethanol, and lipid rafts: a new mechanism of ethanol action with implications for other receptor-mediated effects, J. Immunol., 2007, 178(3), 1243-1249.

37 R. C. Murphy, Fatty acids, Tandem Mass Spectrometry of Lipids: Molecular Analysis of Complex Lipids, in New Development in Mass Spectrometry. Tandem Mass Spectrometry of Lipids, No. 4, ed. R.C. Murphy, Royal Society of Chemistry, Cambridge, 2015, pp. 1:1-1:39.

38 E. Hurtado Fernández, Avocado (Persica Americana): complementarity of different omics technologies for its metabolic characterization, Dissertation, University of Granada, 2014.

39 K. Strassburg, B. J. Molly, C. Mallet, A. Duesterloh, I. Bendik, T. Hankemeier, J. Langridge, R. J. Vreeken and G. Astarita, Targeted lipidomics of oxylipins (oxygenated fatty acids), in Waters Application Note, Waters Corporation, Milford, 2015, pp. 1-11.

40 R. E. Duderstadt and S. M. Fischer, Effect of organic mobile phase composition on signal responses for selected polyalkene additive compounds by liquid chromatographymass spectrometry, J. Chromatogr. A, 2008, 1193, 70-78, DOI: 10.1016/j.chroma.2008.03.086.

41 F. Stickel and D. Schuppan, Herbal medicine in the treatment of liver diseases, Dig. Liver Dis, 2007, 39, 293304.

42 M. Wink, Modes of Action of Herbal Medicines and Plant Secondary Metabolites, Medicines, 2015, 2(3), 251-286, DOI: 10.3390/medicines2030251.

43 M. Wink, Evolutionary advantage and molecular modes of action of multi-component mixtures used in phytomedicine, Curr. Drug Metab., 2008, 9(10), 996-1009.

44 L. C. S. Cunha, S. A. L. de Morais, F. J. T. de Aquino, R. Chang, A. de Oliveira, M. M. Martins, C. H. G. Martins, L. C. F. Sousa, T. T. Barros, C. V. da Silva and E. A. do Nascimento, Bioassay-guided fractionation and antimicrobial and cytotoxic activities of Cassia bakeriana extracts, Rev. Bras. Farmacogn., 2017, 27, 91-98, DOI: 10.1016/j.bjp.2016.08.002.

45 K. Rajamania, T. Balasubramaniana and S. S. Thirugnanasambandana, Bioassay-guided isolation of triterpene from brown alga Padina boergesenii possess antiinflammatory and anti-angiogenic potential with kinetic inhibition of $\beta$-carotene linoleate system, LWT-Food Sci. Technol., 2018, 93, 549-555, DOI: 10.1016/j.lwt.2018.04.010.

46 E. Garayev, C. Di Giorgio, G. Herbette, F. Mabrouki, P. Chiffolleau, D. Roux, H. Sallanon, E. Ollivier, R. Elias and B. Baghdikian, Bioassay-guided isolation and UHPLC-DAD-ESI-MS/MS quantification of potential antiinflammatory phenolic compounds from flowers of Inula montana L, J. Ethnopharmacol., 2018, 226, 176-184, DOI: 10.1016/j.jep.2018.08.005.

47 A. Sudha and P. Srinivasan, A bioassay-guided isolation and antioxidant evaluation of flavonoid compound from aerial parts of Lippia nodiflora L, BioMed Res. Int., 2014, 549836, DOI: 10.1155/2014/549836.

48 W. S. Yang, S. R. Lee, Y. J. Jeong, D. W. Park, C. Mg, H. M. Joo, I. Kim, Y. B. Seu, E. H. Sohn and S. C. Kang, Anti-allergic activity of ethanol extracts of Arctium lappa L. undried roots and its active compound-oleamide-in regulating FceRI-mediated and MAPK signaling in RBL-2H3 cells, J. Agric. Food Chem., 2016, 64(18), 3564-3573, DOI: 10.1021/acs.jafc.6b00425.

49 P. Khuwijitjaru, N. Sayputikasikorn, S. Samuhasaneetoo, P. Penroj, P. Siriwongwilaichat and S. Adachi, Subcritical water extraction of flavoring and phenolic compounds from cinnamon bark (Cinnamomum zeylanicum), J. Oleo Sci., 2012, 61(6), 349-355.

50 J. R. Swider, J. A. Jankowski and A. Sobevski, Direct, realtime mass spectrometry analysis of cinnamon, Am. Lab., 2016, 36-39.

51 L. Thakur, U. Ghodasra, N. Patel and M. Dabhi, Novel approaches for stability improvement in natural medicines, Pharmacogn. Rev., 2011, 5(9), 48-54, DOI: 10.4103/09737847.79099.

52 E. Games, M. Guerreiro, F. R. Santana, N. M. Pinheiro, E. A. de Oliveira, F. D. Lopes, C. R. Olivo, I. F. Tibério, M. A. Martins, J. H. Lago and C. M. Prado, Structurally Related Monoterpenes $p$-Cymene, Carvacrol and Thymol Isolated from Essential Oil from Leaves of Lippia sidoides Cham. (Verbenaceae) Protect Mice against Elastase-Induced Emphysema, Molecules, 2016, 21(10), pii: E1390.

53 L. R. Bonjardim, E. S. Cunha, A. G. Guimarães, M. F. Santana, M. G. Oliveira, M. R. Serafini, A. A. Araújo, A. R. Antoniolli, S. C. Cavalcanti, M. R. Santos and L. J. Quintans-Júnior, Evaluation of the anti-inflammatory and antinociceptive properties of $p$-cymene in mice, $Z$. Naturforsch., C: J. Biosci., 2012, 67(1-2), 15-21.

54 G. Xie, N. Chen, L. W. Soromou, F. Liu, Y. Xiong, Q. Wu, H. Li, H. Feng and G. Liu, $p$-Cymene protects mice against lipopolysaccharide-induced acute lung injury by inhibiting inflammatory cell activation, Molecules, 2012, 17(7), 81598173, DOI: 10.3390/molecules17078159.

55 R. de Cássia da Silveira E Sá, L.N Andrade, R. Dos Reis Barreto de Oliveira and D.P de Sousa, A review on antiinflammatory activity of phenylpropanoids found in essential oils, Molecules, 2014, 19(2), 1459-1480, DOI: 10.3390/ molecules19021459. 
56 P. Vanýsek, in CRC Handbook of Chemistry and Physics, ed. W. M. Haynes, D. R. Lide and T. J. Bruno, CRC Press, Boca Raton, London, New York, 95th edn, 2014, pp. 5:94-5:104.

57 A. Cuadrado and A. R. Nebreda, Mechanisms and functions of p38 MAPK signalling, Biochem. J., 2010, 429(3), 403-417, DOI: $10.1042 / \mathrm{BJ} 20100323$.

58 R. R. Bansode, T. Leung, P. Randolph, L. L. Williams and M. Ahmedna, Cinnamon extract inhibits angiogenesis in zebrafish and human endothelial cells by suppressing VEGFR1, VEGFR2, and PKC-mediated MAP kinase, Food Sci. Nutr., 2013, 1(1), 74-82, DOI: 10.1002/fsn3.13.

59 S. M. Ka, L. Kuoping Chao, J. C. Lin, S. T. Chen, W. T. Li, C. N. Lin, J. C. Cheng, H. L. Jheng, A. Chen and K. F. Hua, A low toxicity synthetic cinnamaldehyde derivative ameliorates renal inflammation in mice by inhibiting NLRP3 inflammasome and its related signaling pathways, Free Radicals Biol. Med., 2016, 91, 10-24, DOI: 10.1016/j. freeradbiomed.2015.12.003.

60 K. Zhang, E. S. Han, T. H. Dellinger, J. Lu, S. Nam, R. A. Anderson, J. H. Yim and W. Wen, Cinnamon extract reduces VEGF expression via suppressing HIF-1 $\alpha$ gene expression and inhibits tumor growth in mice, Mol. Carcinog., 2017, 56(2), 436-446, DOI: 10.1002/mc.22506.

61 Y. Zhang, W. Cao, Y. H. Xie, Q. Yang, X. Q. Li, X. X. Liu and S. W. Wang, The comparison of $\alpha$-bromo-4-chlorocinnamaldehyde and cinnamaldehyde on coxsackie virus B3- induced myocarditis and their mechanisms, Int. Immunopharmacol., 2012, 14(1), 107-113, DOI: 10.1016/j. intimp.2012.06.007.

62 J. Li, T. Liu, L. Wang, X. Guo, T. Xu, L. Wu, L. Qin and W. Sun, Antihyperglycemic and antihyperlipidemic action of cinnamaldehyde in C57BLKS/J db/db mice, J. Tradit. Chin. Med., 2012, 32(3), 446-452.

63 Y. Hagenlocher, I. Bergheim, S. Zacheja, M. Schäffer, S. C. Bischoff and A. Lorentz, Cinnamon extract inhibits degranulation and de novo synthesis of inflammatory mediators in mast cells, Allergy, 2013, 68(4), 490-497, DOI: 10.1111/all.12122.

64 J. Jiang, M. P. Emont, H. Jun, X. Qiao, J. Liao, D. I. Kim and $\mathrm{J}$. Wu, Cinnamaldehyde induces fat cell-autonomous thermogenesis and metabolic reprogramming, Metabolism, 2017, 77, 58-64, DOI: 10.1016/j.metabol.2017.08.006.

65 A. Khan, M. Safdar, M. M. Ali Khan, K. N. Khattak and R. A. Anderson, Cinnamon improves glucose and lipids of people with type 2 diabetes, Diabetes Care, 2003, 26(12), 3215-3218.

66 R. Akilen, A. Tsiami, D. Devendra and N. Robinson, Glycated haemoglobin and blood pressure-lowering effect of cinnamon in multi-ethnic Type 2 diabetic patients in the UK: a randomized, placebo-controlled, double-blind clinical trial, Diabetic Med., 2010, 27(10), 1159-1167, DOI: 10.1111/j.1464-5491.2010.03079.x. 